\title{
Investigating the impact of reference assembly choice on genomic analyses in a cattle breed
}

\author{
Audald Lloret-Villas ${ }^{1 *}$, Meenu Bhati ${ }^{1}$, Naveen Kumar Kadri ${ }^{1}$, Ruedi Fries ${ }^{2}$ and Hubert Pausch ${ }^{1}$
}

\begin{abstract}
Background: Reference-guided read alignment and variant genotyping are prone to reference allele bias, particularly for samples that are greatly divergent from the reference genome. A Hereford-based assembly is the widely accepted bovine reference genome. Haplotype-resolved genomes that exceed the current bovine reference genome in quality and continuity have been assembled for different breeds of cattle. Using whole genome sequencing data of 161 Brown Swiss cattle, we compared the accuracy of read mapping and sequence variant genotyping as well as downstream genomic analyses between the bovine reference genome (ARS-UCD1.2) and a highly continuous Angus-based assembly (UOA_Angus_1).
\end{abstract}

Results: Read mapping accuracy did not differ notably between the ARS-UCD1.2 and UOA_Angus_1 assemblies. We discovered 22,744,517 and 22,559,675 high-quality variants from ARS-UCD1.2 and UOA_Angus_1, respectively. The concordance between sequence- and array-called genotypes was high and the number of variants deviating from Hardy-Weinberg proportions was low at segregating sites for both assemblies. More artefactual INDELs were genotyped from UOA_Angus_1 than ARS-UCD1.2 alignments. Using the composite likelihood ratio test, we detected 40 and 33 signatures of selection from ARS-UCD1.2 and UOA_Angus_1, respectively, but the overlap between both assemblies was low. Using the 161 sequenced Brown Swiss cattle as a reference panel, we imputed sequence variant genotypes into a mapping cohort of 30,499 cattle that had microarray-derived genotypes using a two-step imputation approach. The accuracy of imputation (Beagle $R^{2}$ ) was very high (0.87) for both assemblies. Genome-wide association studies between imputed sequence variant genotypes and six dairy traits as well as stature produced almost identical results from both assemblies.

Conclusions: The ARS-UCD1.2 and UOA_Angus_1 assemblies are suitable for reference-guided genome analyses in Brown Swiss cattle. Although differences in read mapping and genotyping accuracy between both assemblies are negligible, the choice of the reference genome has a large impact on detecting signatures of selection that already reached fixation using the composite likelihood ratio test. We developed a workflow that can be adapted and reused to compare the impact of reference genomes on genome analyses in various breeds, populations and species.

Keywords: Reference genome comparison, Bovine, Alignment quality, Sequence variants, Functional annotation, Signatures of selection, Genome-wide association study

${ }^{*}$ Correspondence: avillas@ethz.ch

'Animal Genomics, ETH Zürich, 8315 Lindau, Switzerland

Full list of author information is available at the end of the article

(C) The Author(s). 2021 Open Access This article is licensed under a Creative Commons Attribution 4.0 International License, which permits use, sharing, adaptation, distribution and reproduction in any medium or format, as long as you give appropriate credit to the original author(s) and the source, provide a link to the Creative Commons licence, and indicate if changes were made. The images or other third party material in this article are included in the article's Creative Commons licence, unless indicated otherwise in a credit line to the material. If material is not included in the article's Creative Commons licence and your intended use is not permitted by statutory regulation or exceeds the permitted use, you will need to obtain permission directly from the copyright holder. To view a copy of this licence, visit http://creativecommons.org/licenses/by/4.0/. The Creative Commons Public Domain Dedication waiver (http://creativecommons.org/publicdomain/zero/1.0/) applies to the data made available in this article, unless otherwise stated in a credit line to the data. 


\section{Background}

Representative reference genomes are paramount for genome research. A reference genome is an assembly of digital nucleotides that are representative of a species' genetic constitution. Like the coordinate system of a two-dimensional map, the coordinates of the reference genome unambiguously point to nucleotides and annotated genomic features. Because the physical position and alleles of sequence variants are determined according to reference coordinates, the adoption of a universal reference genome is required to compare findings across studies. Otherwise, the conversion of genomic coordinates between assemblies is necessary [1]. Updates and amendments to the reference genome change the coordinate system.

Reference genomes of important farm animal species including cattle, pig and chicken were assembled more than a decade ago using bacterial artificial chromosome and whole-genome shotgun sequencing [2-4]. The initial reference genome of domestic cattle (Bos taurus taurus) was generated from a DNA sample of the inbred Hereford cow «L1 Dominette 01449» $[3,5]$. An annotated bovine reference genome enabled systematic assessment and characterization of sequence variation within and between cattle populations using reference-guided alignment and variant detection [3, 6]. A typical genome-wide alignment of DNA sequences from a $B$. taurus taurus individual differs at between 6 and 8 million single nucleotide polymorphisms (SNPs) and small ( $<50 \mathrm{bp})$ insertions and deletions (INDELs) from the reference genome $[7,8]$. More variants are detected in cattle with greater genetic distance from the Hereford breed [9]. The bovine reference genome neither contains allelic variation nor nucleotides that are private to animals other than $\ll \mathrm{L} 1$ Dominette $01449 \gg$. As a result, read alignments may be erroneous particularly at genomic regions that differ substantially between the sequenced individual and the reference genome [10]. The use of consensus reference genomes or variation-aware reference graphs may mitigate this type of bias [11-13].

The quality of reference genomes improved spectacularly over the past 15 years. Decreasing error rates and increasing outputs of long-read $(>10 \mathrm{~Kb})$ sequencing technologies such as PacBio single molecule realtime (SMRT) [14] and Oxford Nanopore sequencing [15] revolutionised the assembly of reference genomes. Sophisticated genome assembly methods enable to assemble gigabase-sized and highly-repetitive genomes from long sequencing reads at high continuity and accuracy [16-18]. The application of "trio-binning" [19] facilitates the de novo assembly of haplotype-resolved genomes that exceed in quality and continuity all previously assembled reference genomes. This approach now offers an opportunity to obtain reference-quality genome assemblies and identify hitherto undetected variants in non-reference sequences, thus making the full spectrum of sequence variation amenable to genetic analyses $[17,19]$.

Reference-quality assemblies are available for Hereford (ARS-UCD1.2) [20], Angus (UOA_Angus_1) [17] and Highland cattle [21]. In addition, reference-quality assemblies are available for yak (Bos grunniens) [21] and Brahman (Bos taurus indicus) [17] which are closely related to taurine cattle. Any of these resources may serve as a reference for reference-guided sequence read alignment, variant detection and annotation. Linear mapping and sequence variant genotyping accuracy may be affected by the choice of the reference genome and the divergence of the DNA sample from the reference genome [22-25]. It remains an intriguing question, which reference genome enables optimum read mapping and variant detection accuracy for a particular animal [11-13].

Here, we assessed the accuracy of reference-guided read mapping and sequence variant detection in 161 Brown Swiss (BSW) cattle using two highly continuous bovine genome assemblies that were created from Hereford (ARS-UCD1.2) and Angus (UOA_Angus_1) cattle. Moreover, we detect signatures of selection and perform sequence-based association studies to investigate the impact of the reference genome on downstream genomic analyses.

\section{Results}

Short paired-end whole-genome sequencing reads of 161 BSW cattle (113 males, 48 females) were considered for our analysis. All raw sequencing data are publicly available at the Sequencing Read Archive of the NCBI [26] or the European Nucleotide Archive of the EMBL-EBI [27]. Accession numbers are listed in the Supplementary File 1: Table S1.

\section{Alignment quality and depth of coverage}

Following the removal of adapter sequences, and reads and bases of low sequencing quality, between 173 and 1,411 million reads per sample (mean: $360 \pm 165$ million reads) were aligned to expanded versions of the Herefordbased ARS-UCD1.2 and the Angus-based UOA_Angus_1 assemblies that included sex chromosomal sequences and unplaced scaffolds (see Material and Methods) using a reference-guided alignment approach. The Hereford assembly is a primary assembly because it was created from a purebred animal [20]. The Angus assembly is haplotype-resolved because it was created from an Angus $x$ Brahman cross using "trio-binning" [17]. The average number of reads per sample that aligned to sex chromosomes, the mitochondrial genome and unplaced contigs were slightly higher for UOA_Angus_1 (66 \pm 39 million) than ARS-UCD1.2 (64 \pm 38 million). 
We considered the 29 autosomes to investigate alignment quality. The total length of the autosomes was 2,489,385,779 bp for ARS-UCD1.2 and 2,468,157,877 bp for UOA_Angus_1. An average number of $295 \pm 131$ and $293 \pm 130$ million reads per sample aligned to autosomal sequences of ARS-UCD1.2 and UOA_Angus_1, respectively. The slightly higher number of reads that mapped to ARS-UCD1.2 is likely due to its longer autosomal sequence. In order to ensure consistency across all analyses performed, we retained $263 \pm 118$ (89.28\%) and 261 $\pm 117(89.17 \%)$ uniquely mapped and properly paired reads (i.e., all reads except those with a SAM-flag value of 1796) that had mapping quality higher than 10 (highquality reads hereafter) per sample, as such reads qualify for sequence variant genotyping using the best practice guidelines of the Genome Analysis Toolkit (GATK) [28, 29] (Table 1). The number of reads that mapped to the autosomes but were discarded due to low mapping quality (either SAM-flag 1796 or MQ <10) were almost identical (32 \pm 20 million) for both assemblies (Supplementary File 2: Table S2). Most of the discarded reads $(83.37 \%$ for ARS-UCD1.2 and 82.29\% for UOA_Angus_1) were flagged as duplicates.

The mean percentage of high-quality reads was slightly higher $(0.10 \pm 0.63)$ for the ARS-UCD1.2 than UOA_Angus_1 autosomes but greater differences existed at some chromosomes. The proportion of high-quality reads was higher for the ARS-UCD1.2 assembly than the UOA_Angus_1 assembly at 16 out of the 29 autosomes. The greatest difference was observed for chromosome 20 , for which the proportion of high-quality reads was 2.03 percent points greater for the ARS-UCD1.2 assembly than the UOA_Angus_1 assembly $\left(\mathrm{P}=4.5 \times 10^{-4}\right)$. Of $8.59 \pm 3.81$ and $8.69 \pm 3.88$ million reads that aligned to chromosome 20 of ARS-UCD1.2 and UOA_Angus_1, respectively, $7.66 \pm 3.42$ and $7.57 \pm 3.38$ million were high-quality reads. Among the 13 autosomes for which the percentage of high-quality reads was greater for the UOA_Angus_1 than ARS-UCD1.2 assembly, the greatest difference ( 0.75 percent points) was observed for chromosome 13.

Average genome coverage ranged from 8.8- to 62.4-fold per sample for both assemblies. The mean coverage of the BAM files was nearly identical for the ARS-UCD1.2 $(14.13 \pm 7.26)$ and UOA_Angus_1 (14.11 \pm 7.25) assembly. Chromosome wise, no differences were detected $(\mathrm{P}=0.36)$ across the two assemblies considered. The mean coverage was between 13.76 (chromosome 19) and 14.45 (chromosome 27) for ARS-UCD1.2 and between 13.76 (chromosome 19) and 14.52 (chromosome 14) for UOA_Angus_1.

\section{Sequence variant genotyping and variant statistics}

Single nucleotide polymorphisms (SNPs), insertions and deletions (INDELs) were discovered from the BAM files following the GATK best practice guidelines [28, 29]. Using the HaplotypeCaller and GenotypeGVCFs modules of GATK, we detected 24,760,861 and 24,557,291 autosomal variants from the ARS-UCD1.2 and UOA_Angus_1 alignments, respectively, of which 22,744,517 (91.86\%) and 22,559,675 (91.87\%) high-quality variants were retained after applying site-level hard filtration using the VariantFiltration module of GATK (Supplementary File 3: Table S3). The mean transition/transversion ratio was 2.15 for the high-quality variants detected from either of the assemblies.

For 32.40 and $33.80 \%$ of the high-quality variants, the genotype of at least one out of 161 BSW samples was missing using the ARS-UCD1.2 and UOA_Angus_1 alignments, respectively. Across all chromosomes, the number of missing genotypes was slightly higher $(\mathrm{P}=0.087)$ for variants called from UOA_Angus_1 than ARS-UCD1.2 alignments. The percentage of variants with missing genotypes was highest on chromosome 12 in both assemblies. At least one missing genotype was observed for 49.79 and $37.39 \%$ of the chromosome 12 variants for the UOA_Angus_1 and ARS-UCD1.2-called genotypes. Beagle [30] (version 4.1) phasing and imputation was

Table 1 Mapping statistics for the 161 BSW samples

\begin{tabular}{|c|c|c|c|}
\hline Parameter & Unit & ARS-UCD1.2 & UOA_Angus_1 \\
\hline \multirow[t]{2}{*}{ Autosomal reads } & Million & 47,502 & 47,128 \\
\hline & Million / sample & $295 \pm 131$ & $293 \pm 130$ \\
\hline \multirow[t]{4}{*}{ Autosomal high-quality reads } & Million & 42,418 & 42,029 \\
\hline & Million / sample & $263 \pm 118$ & $261 \pm 117$ \\
\hline & $\%$ / sample & $89.28 \pm 5.06$ & $89.17 \pm 5.06$ \\
\hline & $\%$ / chromosome & $89.28 \pm 0.34$ & $89.17 \pm 0.56$ \\
\hline \multirow[t]{2}{*}{ Coverage } & fold / sample & $14.13 \pm 7.26$ & $14.11 \pm 7.25$ \\
\hline & fold / chromosome & $14.13 \pm 0.14$ & $14.11 \pm 0.15$ \\
\hline
\end{tabular}

Summary statistics extracted from the BAM files after aligning the samples to either the ARS-UCD1.2 or UOA_Angus_1 assembly. Uniquely mapped and properly paired reads with MQ >10 are considered as high-quality reads. The percentage of autosomal reads that are high-quality reads is calculated per sample and per chromosome. Coverage of high-quality reads is calculated per sample and per chromosome 
Table 2 Comparisons between array-called and sequence variant genotypes

\begin{tabular}{llllllll}
\hline & \multicolumn{2}{l}{ GATK hard filtering } & & & \multicolumn{3}{l}{ GATK hard filtering + Beagle imputation } \\
\cline { 2 - 3 } & NRS & NRD & CONC & & NRS & NRD & CONC \\
\hline ARS-UCD1.2 & 99.14 & 2.75 & 98.13 & & 99.77 & 0.60 & 99.59 \\
UOA_Angus_1 & 99.37 & 2.45 & 98.09 & & 99.88 & 0.47 & 99.64 \\
\hline
\end{tabular}

Non-reference sensitivity (NRS), non-reference discrepancy (NRD) and the concordance (CONC) between array-called and sequence-called genotypes for 112 BSW cattle that had BovineHD and sequence-called genotypes at 530,372 autosomal SNPS

applied to improve the genotype calls from GATK and impute the missing genotypes.

112 sequenced animals that had an average fold sequencing coverage of $13.47 \pm 6.45$ and $13.46 \pm$ 6.44 when aligned to ARS-UCD1.2 and UOA_Angus_1, respectively, also had Illumina BovineHD array-called genotypes at 530,372 autosomal SNPs. We considered the microarray-called genotypes as a truth set to calculate non-reference sensitivity, non-reference discrepancy and the concordance between array-called and sequence-called genotypes (Table 2). The average concordance between array- and sequence-called genotypes was greater than 98 and $99.5 \%$ before and after Beagle imputation, respectively, for variants called from both assemblies. We observed only slight differences in the concordance metrics between variants called from either ARS-UCD1.2 or UOA_Angus_1, indicating that the genotypes of the 112 BSW cattle were accurately called from both assemblies, and that Beagle phasing and imputation further increased the genotyping accuracy.

Because Beagle phasing and imputation improved the genotype calls from GATK, the subsequent analyses are based on the imputed sequence variant genotypes. After imputation, 81,674 (0.36\%, 72,121 SNPs, 9,553 INDELs) and 104,217 (0.46\%, 75,342 SNPs, 28,875 INDELs) variants were fixed for the alternate allele in ARS-UCD1.2 and UOA_Angus_1, respectively (Supplementary File 3: Table S3). Both the number and the percentage of variants fixed for the alternate allele was higher $(0.10$ percent points the latter, $P=0.027$ ) for the UOA_Angus_1 than the ARS-UCD1.2 assembly. While the proportion and number of SNPs fixed for the alternate allele did not differ significantly $(P=0.65)$ between the assemblies, 0.61 percent points more INDELs $\left(\mathrm{P}=1.45 \times 10^{-9}\right)$ were fixed for the alternate allele in UOA_Angus_1 than ARS-UCD1.2. $22,488,261$ and $22,289,905$ variants were polymorphic (i.e., minor allele count $\geq 1$ ) among the $161 \mathrm{BSW}$ animals in ARS-UCD1.2 and UOA_Angus_1, respectively (Table 3). The number of variants detected per sample ranged from 6.91 to 8.58 million $(7.28 \pm 0.15)$ in ARSUCD1.2 and from 6.93 to 8.44 million $(7.26 \pm 0.15)$ in UOA_Angus_1. More SNPs and INDELs were discovered for the ARS-UCD1.2 than UOA_Angus_1 assembly.

To take the length of the autosomes into consideration, we calculated the number of variants per $\mathrm{Kb}$. While the overall variant and INDEL density was slightly higher for the ARS-UCD1.2 assembly, the SNP density was slightly higher for the UOA_Angus_1 assembly (Table 3).

The number and density of high-quality variants segregating on the 29 autosomes was $2.04(\mathrm{P}=0.51)$ and $0.45(\mathrm{P}=0.39)$ percent points higher, respectively, for the ARS-UCD1.2 than the UOA_Angus_1 assembly (Fig. 1, Supplementary File 4: Figure S1). The difference in the number of variant sites detected from both assemblies was lower for SNPs (1.71 percent points) than INDELs (4.28 percent points). Chromosomes 9 and 12 were the only autosomes for which more variants were detected using the UOA_Angus_1 than ARS-UCD1.2 assembly. Differences in the number of variants detected were evident for chromosomes 12 and 28. While chromosome 12 has $29 \%$ more variants when aligned to UOA_Angus_1, chromosome 28 has $31 \%$ more variants when aligned to ARS-UCD1.2.

The variant density of 26 out of the 29 autosomes (except for chromosomes 9,12 and 26) was higher for the ARS-UCD1.2 assembly than the UOA_Angus_1 assembly. However, the density of INDELs was only higher for chromosome 12. Chromosome 23 had a higher variant density than all other chromosomes for both assemblies, with an average number of 13 variants detected per $\mathrm{Kb}$. The high variant density at chromosome 23 primarily resulted from an excess of polymorphic sites within a $\sim 5 \mathrm{Mb}$ segment (between 25 and $30 \mathrm{Mb}$ in the ARS-UCD1.2 and between 22 and $27 \mathrm{Mb}$ in UOA_Angus_1) encompassing the bovine major histocompatibility complex (BoLA) (Supplementary File 5: Figure S2). Other autosomes with density above 10 variants per $\mathrm{Kb}$ for both assemblies were chromosomes 12, 15 and 29. We observed the least variant density $(\sim 8$ variants per $\mathrm{Kb})$ at chromosome 13 .

Table 3 Variants segregating among 161 BSW samples

\begin{tabular}{lll}
\hline & ARS-UCD1.2 & UOA_Angus_1 \\
\hline Non-fixed variants (per Kb) & $22,488,261(9.03)$ & $22,289,905(9.03)$ \\
Non-fixed SNPs (per Kb) & $19,557,039(7.86)$ & $19,446,648(7.88)$ \\
Non-fixed INDELs (per Kb) & $2,931,222(1.18)$ & $2,843,257(1.15)$ \\
\hline
\end{tabular}

Number of high-quality non-fixed variants discovered after aligning the samples to ARS-UCD1.2 and UOA_Angus_1 assemblies. Numbers in parentheses reflect the variant density (number of variants per Kb) along the autosomes 


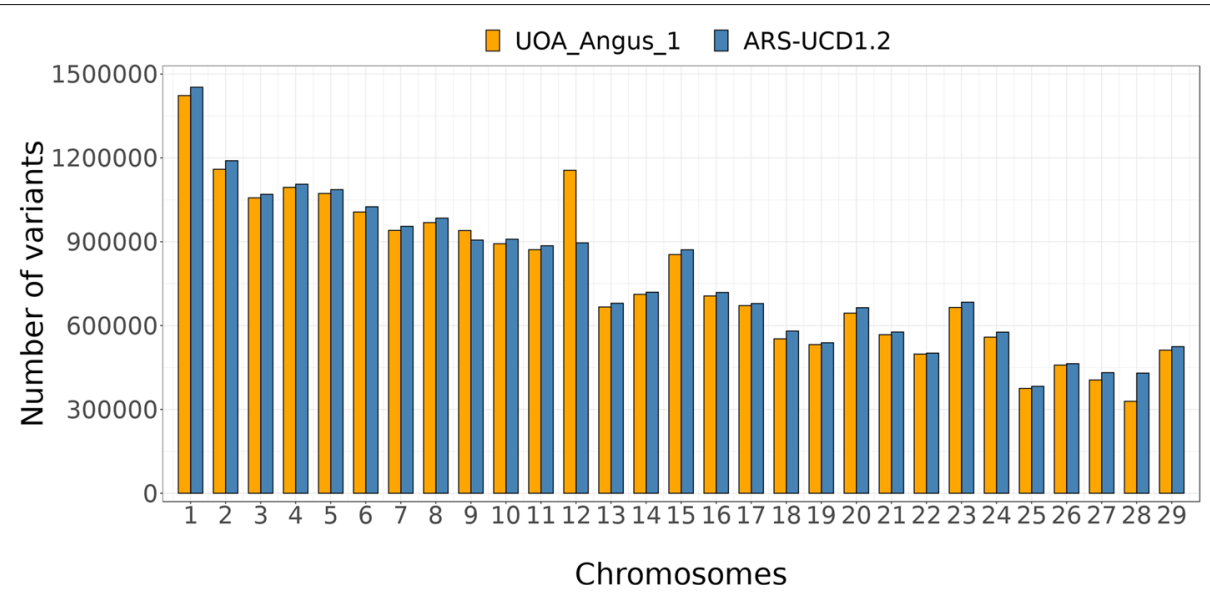

Fig. 1 Total number of variants of autosomes for both assemblies. Number of variants detected on autosomes when the 161 BSW samples are aligned to the ARS-UCD1.2 (blue) and UOA_Angus_1 (orange) assembly

Chromosome 12 carries a segment with an excess of variants at $\sim 70 \mathrm{Mb}$ in both assemblies. Visual inspection revealed that the segment with an excess of polymorphic sites was substantially larger in UOA_Angus_1 (7.6 $\mathrm{Mb}$ ) than ARS-UCD1.2 (3.5 Mb) (Fig. 2). The variant-rich region at chromosome 12 coincides with a large segmental duplication that compromises reference-guided variant genotyping from short-read sequencing data and that has been described earlier [31-33]. Because of the greater number of variants and variant density in UOA_Angus_1, this extended region had a large impact on the cumulative genome-wide metrics presented in Table 3. When the same metrics were calculated without chromosome 12, the average density of both SNPs and INDELs was higher for ARS-UCD1.2 than UOA_Angus_1 (Supplementary File 6: Table S4). Segments with an excess of polymorphic sites were also detected on the ARS-UCD1.2 chromosomes 4 (113-114 Mb), 5 (98-105 $\mathrm{Mb}), 10(22-26 \mathrm{Mb}), 18$ (60-63 Mb), and 21 (20-21 $\mathrm{Mb})$. The corresponding regions in the UOA_Angus_1 assembly showed the same excess of polymorphic sites. However, these regions were shorter, and their variant density was lower compared to the extended segment at chromosome 12 . The strikingly higher number $(+31 \%)$ of variants discovered at chromosome 28 for ARSUCD1.2 than UOA_Angus_1 was due to an increased length of chromosome 28 in the ARS-UCD1.2 assembly (Fig. 2).

Of $22,488,261$ and $22,289,905$ high-quality nonfixed variants, 848,100 (3.78\%) and 857,206 (3.83\%) had more than two alleles in the ARS-UCD1.2 and UOA_Angus_1 alignments, respectively (Supplementary File 7: Table S5). Most (69.75\% for ARS-UCD1.2 and 69.09\% for UOA_Angus_1) of the multi-allelic sites were INDELs. The difference in the percentage of multiallelic
SNPs across assemblies was negligible. However, the difference in percentage of multiallelic INDELs was 0.69 percent points higher $\left(\mathrm{P}=2.55 \times 10^{-9}\right)$ for UOA_Angus_1 than ARS-UCD1.2 autosomes.

In order to detect potential flaws in sequence variant genotyping, we investigated if the genotypes at the highquality non-fixed variants agreed with Hardy-Weinberg proportions. We observed 218,734 (0.97\%) and 243,408 (1.09\%) variants for ARS-UCD1.2 and UOA_Angus_1, respectively, for which the observed genotypes deviated significantly $\left(\mathrm{P}<10^{-8}\right.$, Supplementary File 7: Table S5) from expectations. The proportion of high-quality nonfixed variants for which the genotypes do not agree with Hardy-Weinberg proportions is 0.12 percent points higher for the UOA_Angus_1 than ARS-UCD1.2 assembly. At chromosome 12, 3.29 percent points more variants deviated from Hardy-Weinberg proportions for the UOA_Angus_1 than the ARS-UCD1.2 assembly (Supplementary File 8: Figure S3); more than twice the difference observed for any other autosome. When variants located on chromosome 12 were excluded from this comparison, we observed 199,304 (0.92\%) and 180,264 (0.85\%) variants for the ARS-UCD1.2 and UOA_Angus_1 assembly, respectively, for which the observed genotypes deviated significantly $\left(\mathrm{P}<10^{-8}\right)$ from expectations.

\section{Functional annotation of polymorphic sites}

Using the VEP software, we predicted functional consequences based on the Ensembl genome annotation for 19,557,039 and 19,446,648 SNPs, and 2,931,222 and 2,843,257 INDELs, respectively, that were discovered from the ARS-UCD1.2 and UOA_Angus_1 alignments. Most SNPs were in either intergenic $(66.30 \%$ and $56.56 \%)$ or intronic regions $(32.55 \%$ and $42.09 \%)$ for 
a

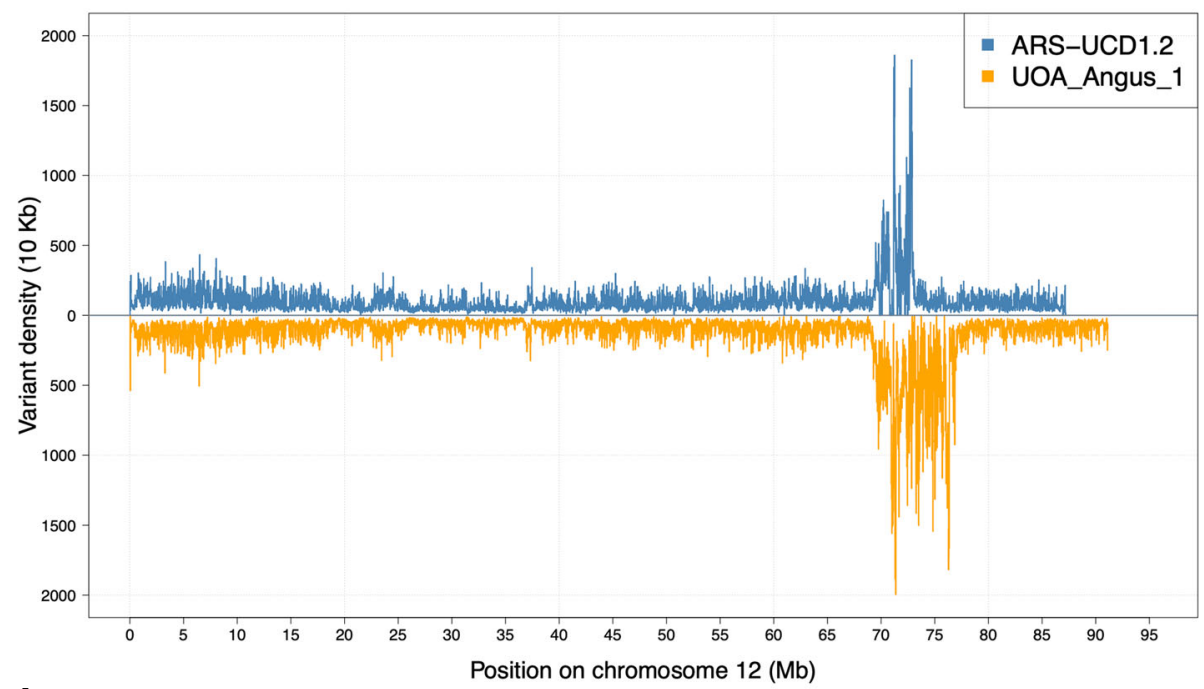

b

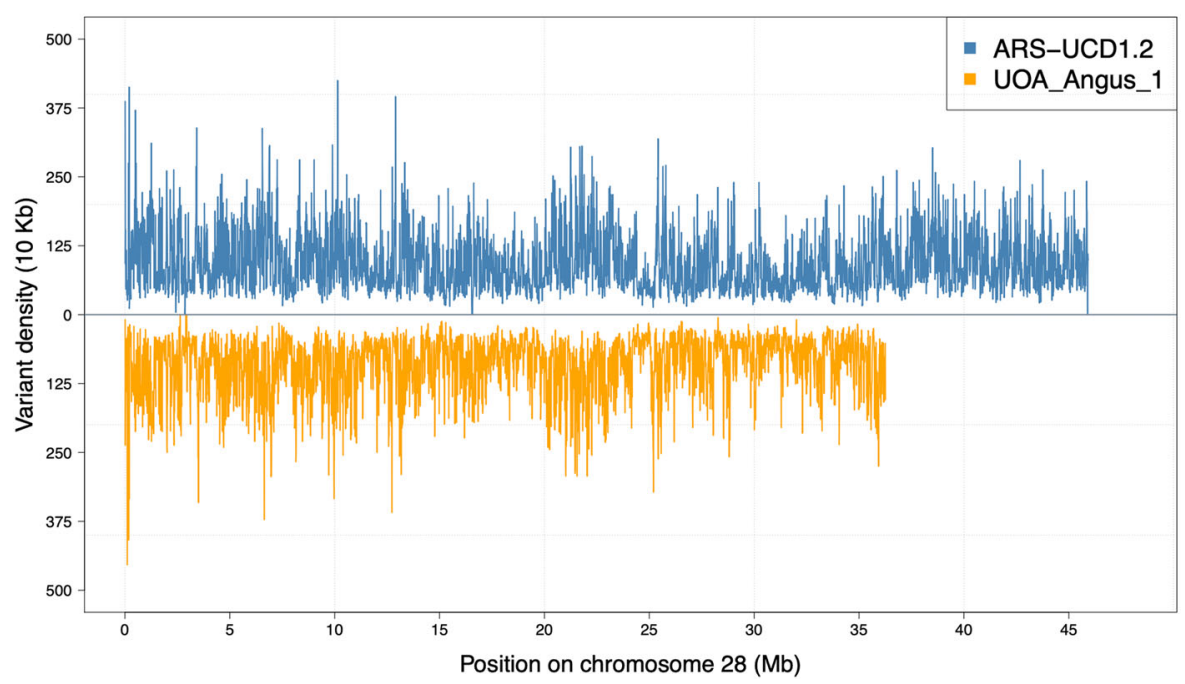

Fig. 2 Density of variants across chromosomes 12 and 28. The number of variants within non-overlapping windows of $10 \mathrm{~Kb}$ for chromosome 12 (a) and 28 (b). The $x$-axis indicates the physical position along the chromosome (in Mb). The number of variants within each $10 \mathrm{~Kb}$ window is shown on the $y$-axis. Assembly ARS-UCD1.2 is displayed above the horizontal line (blue) and assembly UOA_Angus_1 is displayed below the horizontal line (orange)

ARS-UCD1.2 and UOA_Angus_1, respectively (Table 4, Supplementary File 9: Table S6). Only 224,549 and 262,775 $(1.15 \%$ and $1.35 \%)$ of the SNPs were in exons for ARSUCD1.2 and UOA_Angus_1, respectively. The majority of INDELs was in either intergenic $(65.76 \%$ and $55.95 \%)$ or intronic regions $(33.84 \%$ and $43.47 \%)$ for ARS-UCD1.2 and UOA_Angus_1, respectively (Table 4, Supplementary File 9: Table S6). Only 11,561 and 16,391 $(0.40 \%$ and $0.58 \%)$ INDELs were in exonic sequences. While the number and proportion of variants in coding regions was similar for both assemblies, we observed marked differences in the number of variants annotated to intergenic and intronic regions. The percentage of SNPs and INDELs annotated to intergenic regions is 9.74 and 9.81 percent points higher, respectively, for the ARS-UCD1.2 than UOA_Angus_1 assembly. In contrast, the percentage of SNPs and INDELs annotated to intronic regions is 9.54 and 9.63 percent points higher, respectively, for the UOA_Angus_1 than the ARSUCD1.2 assembly. According to the Ensembl annotation of the autosomal sequences, intergenic, intronic and exonic regions span respectively $61.53,34.77$ and $3.80 \%$ in ARS-UCD1.2 and 52.32, 42.32 and $5.36 \%$ in UOA_Angus_1. 
Table 4 Number of SNPS and INDELs annotated using the VEP software per region and assembly

\begin{tabular}{|c|c|c|c|c|}
\hline & \multicolumn{2}{|l|}{ ARS-UCD1.2 } & \multicolumn{2}{|l|}{ UOA_Angus_1 } \\
\hline & SNPs & INDELS & SNPs & INDELs \\
\hline Exonic regions (\%) & $224,549(1.15)$ & $11,561(0.40)$ & $262,775(1.35)$ & $16,391(0.58)$ \\
\hline Intronic regions (\%) & $6,365,765(32.55)$ & $992,015(33.84)$ & $8,185,503(42.09)$ & $1,236,006(43.47)$ \\
\hline Intergenic regions (\%) & $12,966,725$ (66.30) & $1,927,646(65.76)$ & $10,998,370(56.56)$ & $1,590,860(55.95)$ \\
\hline
\end{tabular}

Annotated SNPs and INDELs are classified by region where detected. The total number of annotated variants per assembly and region are displayed here. The table lists only the most severe annotation. The percentage of variants placed in each region per variant type and assembly is shown between parentheses

Either moderate or high impacts on protein function were predicted for 89,812 and 103,576 SNPs, and 10,259 and 11,847 INDELs $(0.46$ and $0.53 \%$ of the total annotated SNPs and 0.35 and $0.41 \%$ of the total annotated INDELs), respectively, that were discovered from ARS-UCD1.2 and UOA_Angus_1 alignments (Tables 5 and 6). The number of variants with putatively high or moderate effects was higher for the UOA_Angus_1 than ARS-UCD1.2 assembly for 14 of 16 functional classes of annotations. Differences across all autosomes were observed for SNPs that potentially affect splice acceptor variants (345 for ARS-UCD1.2 and 395 for UOA_Angus_1, P = 0.032) and SNPs that potentially cause the loss of a stop codon (155 for ARS-UCD1.2 and 218 for UOA_Angus_1, P = 0.037). Differences across all autosomes also resulted for INDELs that potentially cause inframe deletions $(1,761$ for ARS-UCD1.2 and 1,972 for UOA_Angus_1, P = 0.0035), INDELs that potentially cause inframe insertions (850 for ARS-UCD1.2 and 985 for UOA_Angus_1, P=0.0013) and INDELs that potentially cause the gain of a stop codon (218 for ARS-UCD1.2 and 288 for UOA_Angus_1, P = $0.016)$.

\section{Signatures of selection}

Next, we investigated how the choice of the reference genome impacts the detection of putative signatures of selection in the $161 \mathrm{BSW}$ cattle. We used the composite likelihood ratio (CLR) test to identify beneficial adaptive alleles that are either close to fixation or recently reached fixation [34]. As information on ancestral and derived

Table 5 SNPs in high or moderate effect categories

\begin{tabular}{lll}
\hline & ARS-UCD1.2 & UOA_Angus_1 \\
\hline Missense variant* & 86,634 & 99,773 \\
Stop gained & 1,466 & 1,911 \\
Splice donor variant & 506 & 525 \\
Splice acceptor variant & 345 & 395 \\
Start lost & 271 & 319 \\
Stop lost & 155 & 218 \\
\hline
\end{tabular}

Number of SNPs in high and moderate (marked with an asterisk) effect categories per assembly alleles was not available, we considered 19,370,683 (ARSUCD1.2) and 19,255,155 (UOA_Angus_1) sequence variants that were either polymorphic or fixed for the alternate allele in the $161 \mathrm{BSW}$ cattle. The CLR test revealed 40 and 33 genomic regions (merged top 0.1\% windows) encompassing $\sim 2.5$ and $\sim 2.48 \mathrm{Mb}$, and 29 and 27 genes, respectively, from the ARS-UCD1.2 and the UOA_Angus_1 alignments (Fig. 3, Supplementary File 10: Table S7, Supplementary File 11: Table S8).

A putative signature of selection on chromosome 6 encompassing the NCAPG gene had high CLR values in both assemblies $\left(C_{\text {CR }}\right.$ ARS $-U C D 1.2=4064 ;$ CLR $_{U O A \_A n g u s \_1}$ $=3838$ ). Another signature of selection was detected for both assemblies upstream the KITLG gene on chromosome 5 (ARS-UCD1.2: 18.48 - $18.86 \mathrm{Mb}, \mathrm{CLR}_{A R S-U C D 1.2}$ = 655; UOA_Angus_1: 18.48 - 18.84, CLR UOA_Angus_1 $_{-}=$ 657). However, most of the signatures of selection were detected for only one assembly. A putative selective sweep on chromosome 13 was identified using the ARS-UCD1.2 but not the UOA_Angus_1 assembly. The putative selective sweep was between 11.5 and $12 \mathrm{Mb}$ encompassing three protein coding (CCDC3, CAMK1D and ENSBTAG00000050894) and one non-coding gene (ENSBTAG00000045070). The top window $(C L R=1373)$ was between $11,962,310$ and $12,022,317 \mathrm{bp}$. In order to investigate why the CLR test revealed strong evidence for the

Table 6 INDELs in high or moderate effect categories

\begin{tabular}{lll}
\hline & ARS-UCD1.2 & UOA_Angus_1 \\
\hline Frameshift variant & 6,289 & 7,435 \\
Inframe deletion* $^{*}$ & 1,761 & 1,972 \\
Inframe insertion* & 850 & 985 \\
Splice donor variant & 291 & 298 \\
Splice acceptor variant & 292 & 292 \\
Stop gained & 218 & 288 \\
Protein altering variant* & 87 & 107 \\
Start lost & 20 & 14 \\
Stop lost & 11 & 15 \\
Transcript ablation & 5 & 6 \\
\hline
\end{tabular}

Number of INDELs in high and moderate (marked with an asterisk) effect categories per assembly 


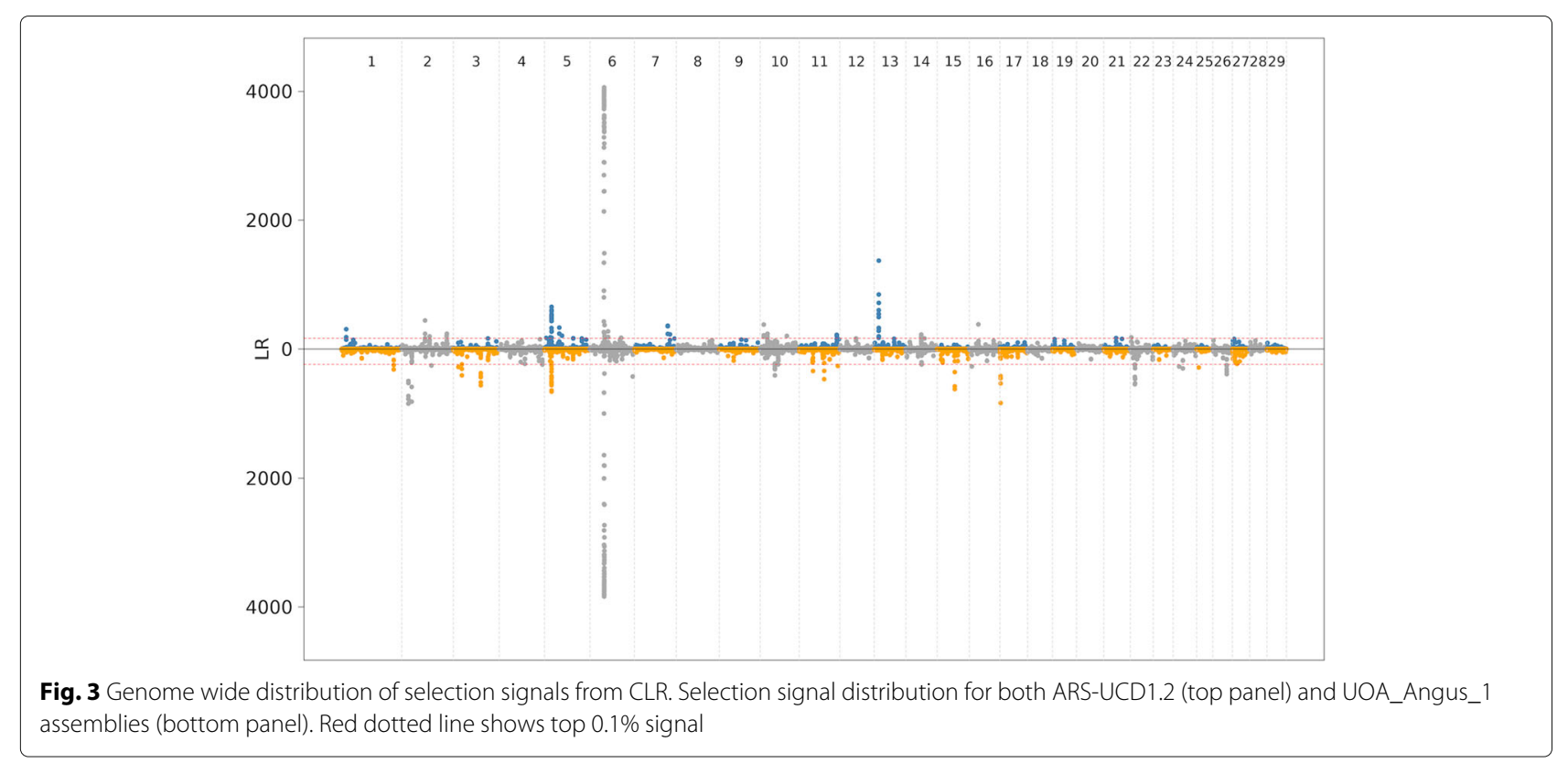

presence of a signature of selection in ARS-UCD1.2 but not in UOA_Angus_1, we investigated the corresponding region in both assemblies using dot plots, variant density, alternate allele frequency and alignment coverage. The dot plot revealed that the orientation of bovine chromosome 13 is flipped in the UOA_Angus_1 assembly. The putative signature of selection is next to but clearly distinct from a region with a very high SNP density and sequence coverage in both assemblies (Supplementary File 12: Figure S4). We detected 350 SNPs within the top window (5.87 SNPs / Kb) of which 145 were fixed for the alternate allele. Within the corresponding region on UOA_Angus_1, we detected 209 SNPs (3.48 SNPs / Kb) of which 13 were fixed for the alternate allele. This pattern indicates that the 161 sequenced BSW cattle carry a segment in the homozygous state that is more similar to the UOA_Angus_1 than ARS-UCD1.2 reference genome. We observed the reciprocal pattern for a putative selective sweep on chromosome 22 that was detected using UOA_Angus_1 but not ARS-UCD1.2 (Supplementary File 13: Figure S5).

\section{Genome-wide association testing}

Next, we imputed genotypes for autosomal variants that were detected using the two assemblies for 30,499 cattle that had (partially imputed) Illumina BovineHD array-derived genotypes. The average imputation accuracy (Beagle $\mathrm{R}^{2}$ ) was $0.87 \pm 0.27$ (median: 0.99) in the ARS-UCD1.2 and $0.87 \pm 0.26$ (median: 0.99 ) in the UOA_Angus_1 assembly. To prevent bias resulting from imputation errors, we removed variants that had low frequency (minor allele count $<3$ ), low accuracy of imputation (Beagle $R^{2}<0.5$ ) or for which the observed genotypes deviated significantly $\left(\mathrm{P}<10^{-6}\right)$ from HardyWeinberg proportions from the imputed data. Following quality control, 12,761,165 and 12,602,069 imputed variants were respectively retained (with imputation accuracy of $0.95 \pm 0.11$ and $0.95 \pm 0.10$ ) for genetic investigations in the ARS-UCD1.2 and UOA_Angus_1 dataset representing 56.75 and $56.54 \%$ of the $22,488,261$ and $22,289,905$ high-quality segregating variants. We then carried out genome-wide association studies (GWAS) between imputed sequence variant genotypes and six traits, including stature and five dairy traits (milk yield, fat yield, protein yield, protein and fat percentage), for which between 11,294 and 12,396 cattle had phenotypes in the form of de-regressed proofs. The resulting Manhattan plots appeared very similar for both datasets (Fig. 4, Supplementary File 14: Figure S6). Across the six traits analysed, the number of significantly associated variants was similar when the association analyses were performed using imputed sequence variants identified in the two builds. The difference in the number of significantly associated variants $\left(\mathrm{P}<10^{-8}\right)$ between the two builds is mainly due to variants that had $P$-values that were slightly above the threshold of $10^{-8}$ in one but not the other build.

To investigate if causal variants can be readily identified from both assemblies, we inspected the QTL for dairy traits at chromosomes 14 and 20, respectively, for which p.Ala232Lys in DGAT1 encoding Diacylglycerol O-Acyltransferase 1 and p.Phe279Tyr in GHR encoding Growth Hormone Receptor have been proposed as causal variants $[35,36]$. The accuracy of imputation for the Phe279Tyr variant in the GHR gene was 0.92 and 0.88 for the ARS-UCD1.2 and UOA_Angus_1 assembly, respectively. In the association studies for milk yield, fat 


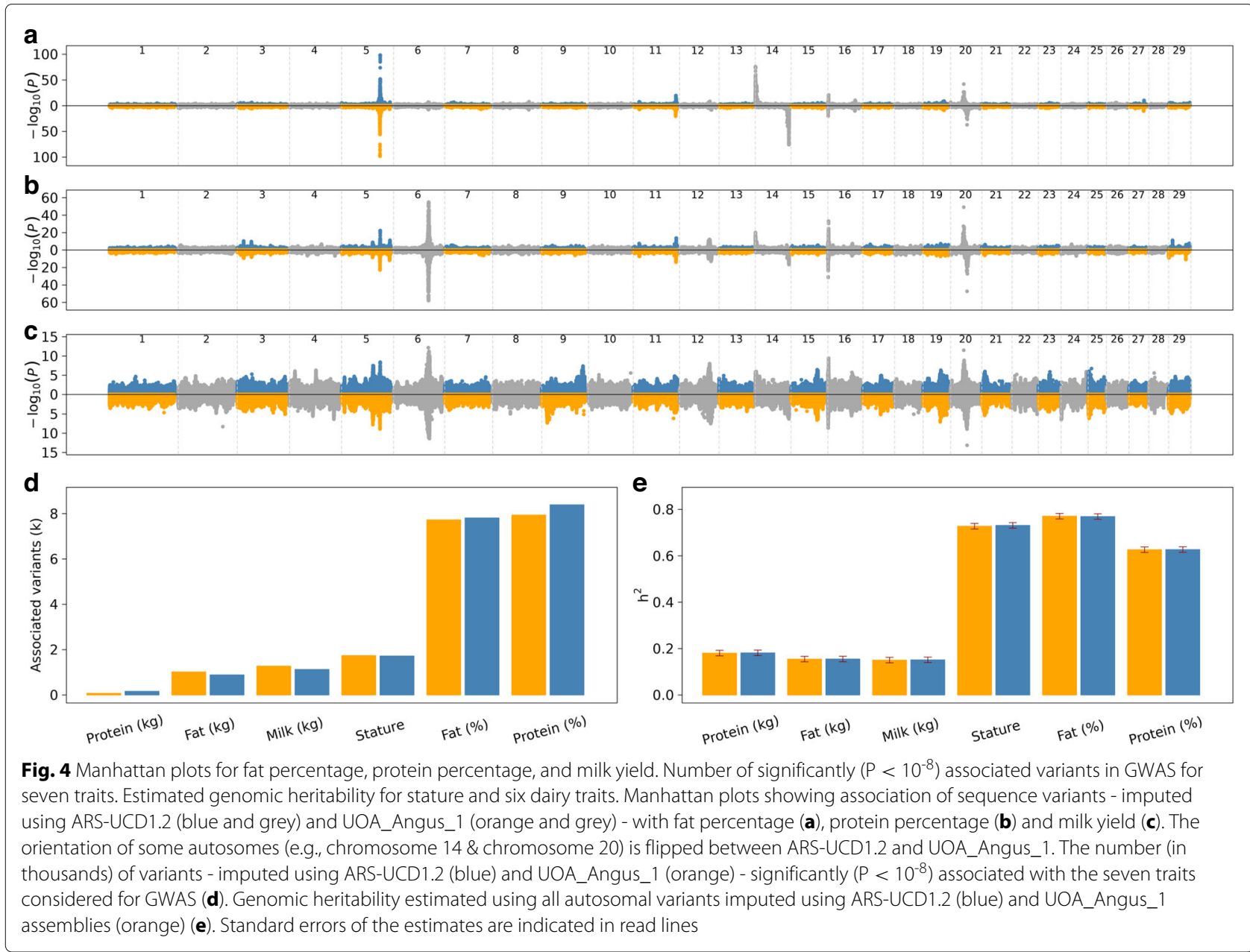

percentage and protein percentage, for which chromosome 20 QTL was detected, the p.Phe279Tyr variant was the most significantly associated variant in both assemblies. The SNP is located at 31,888,449 and 39,903,176 bp on the ARS-UCD1.2 and UOA_Angus_1 build (the orientation of chromosome 20 is flipped in UOA_Angus_1). The frequency of the milk yield-increasing and fat and protein content-decreasing tyrosine-encoding $\mathrm{T}$ allele was 12.90 and $13.02 \%$ in ARS-UCD1.2 and UOA_Angus_1, respectively, and the $P$-values for milk yield, fat percentage and protein percentage were $3.18 \times 10^{-12}, 1.11 \times 10^{-42}$, $6.98 \times 10^{-50}$ and $7.40 \times 10^{-14}, 6.89 \times 10^{-38}, 5.57 \times 10^{-48}$.

Two adjacent SNPs (ARS-UCD1.2: g.611019G $>$ A \& g.611020C $>$ A; UOA_Angus_1: g.81672806C $>$ T \& g.81672805G $>\mathrm{T}$; the orientation of chromosome 14 is flipped in UOA_Angus_1), in the coding sequence of DGAT1 cause the p.Ala232Lys substitution that has a large effect on milk yield and composition. In 161 sequenced BSW cattle of our study, the alternate allele was detected in the heterozygous state in two and one animals using the ARS-UCD1.2 and UOA_Angus_1 datasets. When imputed into array-derived genotypes of the mapping cohort, the lysine variant had a frequency of 0.0082 (Beagle $R^{2}: 0.98$ ) and 0.0002 (Beagle $R^{2}: 0.82$ ) in the ARS-UCD1.2 and UOA_Angus_1 imputed genotypes. An association study between imputed sequence variant genotypes and fat percentage revealed strong association $\left(\mathrm{P}=1.46 \times 10^{-76}\right)$ at the proximal region of chromosome 14 encompassing DGAT1 in the ARS-UCD1.2 data (Fig. 4a). The top association signal resulted from a variant at position 420,486 . The $P$-value of the p.Ala232Lys variant was only slightly higher $\left(\mathrm{P}=2.18 \times 10^{-76}\right)$. Using the UOA_Angus_1 imputed data, we detected strong association at the corresponding region (Fig. 4a). The most significantly associated variant $\left(\mathrm{P}=1.80 \times 10^{-76}\right)$ was at $81,673,955 \mathrm{bp}$. However, the p.Ala232Lys variant was not associated with fat percentage $(\mathrm{P}=0.33)$. Also, the DGAT1 gene was missing in the Ensembl annotation of the UOA_Angus_1 assembly.

Next, we estimated the genomic heritability $\left(h^{2}\right)$ for stature and six dairy traits using a genomic restricted maximum likelihood estimation (GREML) approach. Therefore, we built a genomic relationship matrix separately for each assembly using the genotypes of all imputed 
autosomal variants that had minor allele count $>3$ and imputation accuracy (Beagle $R^{2}$ ) $>0.5$. The estimates for the genomic $\mathrm{h}^{2}$ did not differ for all seven traits (Fig. 4e). We then partitioned (genomic) $\mathrm{h}^{2}$ by the 29 autosomes using the two imputed datasets. As seen for the total $h^{2}$, we found no difference in variance explained by individual autosomes between the two assemblies.

\section{Discussion}

We investigated whether the choice of the reference genome impacts genomic analyses in BSW cattle that have been sequenced with short paired-end reads. To the best of our knowledge, such an evaluation had not been performed so far in cattle. A Hereford-based genome assembly [20] is accepted by the bovine genomics community as reference genome for reference-guided alignment and variant detection in both taurine and indicine cattle $[8,9]$. Recently, the application of sophisticated methods to assemble long sequencing reads provided referencequality assemblies for cattle breeds other than Hereford $[17,21]$. None of these novel reference-quality assemblies has been considered as a reference genome for sequence variant analysis so far. The genetic distance between the reference genome and the target sample and the properties (GC content, genome size, proportion of repeats) of the reference genome impact reference-guided mapping and variant genotyping [17, 24, 25, 37, 38]. To investigate reference-guided sequence analyses from different assemblies, we aligned short sequencing reads of $161 \mathrm{BSW}$ cattle to the Hereford-based ARS-UCD1.2 and Angusbased UOA_Angus_1 assemblies. Widely used metrics (contig N50, scaffold N50, BUSCO completeness) suggest that both assemblies are of reference quality [17, 20]. The sequence read mapping and variant genotyping accuracy did not differ notably between the ARS-UCD1.2 and UOA_Angus_1 assemblies, indicating that both assemblies are suitable for reference-guided genome analyses in BSW cattle. The BSW, Angus and Hereford breeds are closely related as these breeds diverged relatively recently [39]. Greater genetic distance between the target breed and the reference genome might compromise mapping rate and alignment quality [24, 25, 40]. However, it is worth mentioning that the orientation of some chromosomes is flipped in UOA_Angus_1 (i.e., the beginning of the chromosome corresponds to the end in the corresponding ARS-UCD1.2 entry). This does not affect sequence read mapping and variant genotyping but needs to be considered when comparing selection signatures and association signals across assemblies.

The number and density of INDELs that segregate in $161 \mathrm{BSW}$ cattle was slightly lower when variants were called from the UOA_Angus_1 than ARS-UCD1.2 alignment. However, the proportion of multiallelic INDELs and INDELs fixed for the alternate allele was higher in the UOA_Angus_1 than ARS-UCD1.2 alignment. In fact, the absolute number of INDELs fixed for the alternate allele was three times higher when the sequence data were aligned against the UOA_Angus_1 assembly. An excess of artefactual INDELs in long-read sequencingbased assemblies was noted by Watson and Warr [41]. Both the ARS-UCD1.2 and UOA_Angus_1 assembly were constructed from PacBio continuous long reads. While ARS-UCD1.2 was polished with short reads and manually curated, this step was not as extensively carried out for the UOA_Angus_1 assembly $[17,20]$. Our results may indicate that UOA_Angus_1 contains somewhat more artefactual INDELs than ARS-UCD1.2. However, the absolute number of artefactual INDELs is low for both assemblies and their genotypes are likely to be discarded from most downstream analyses as most of them will be fixed for the alternate allele. Importantly, the concordance between sequence- and array-called genotypes was very high and the number of variants deviating from HardyWeinberg proportions was very low at segregating sites for both assemblies, indicating that reliable genotypes can be obtained from both ARS-UCD1.2 and UOA_Angus_1.

The length of chromosomes 12 and 28 differs considerably between the assemblies. A large segmental duplication affects chromosome 12 in both assemblies. This duplication compromises the mapping of sequencing reads, thereby causing misalignments and flaws in the resulting genotypes [31-33]. An excess of variants, including many for which the genotypes deviate from HardyWeinberg proportions, was detected for both assemblies within the segmental duplication. Because the segmental duplication is two times longer in UOA_Angus_1 than ARS-UCD1.2, the genome-wide number of variants, variant density, proportion of missing genotypes and number of variants deviating from Hardy-Weinberg proportions was higher using UOA_Angus_1. At chromosome 28 , the variant density was similar for both assemblies, but the absolute number of variants detected was lower for UOA_Angus_1 because the chromosome was shorter. The UOA_Angus_1 assembly lacks approximately 9.5 million bases that likely correspond to the ARSUCD1.2 chromosome 28 sequence from 36,496,661 bp onwards. According to the Ensembl (build 101) annotation of ARS-UCD1.2, this segment encompasses 67 genes that are consequently missing in the autosomal annotation of UOA_Angus_1.

Differences in the functional annotations predicted for variants obtained from ARS-UCD1.2 and UOA_Angus_1 were evident from the output of the VEP tool. The number of variants annotated to inter- and intragenic regions differed between the assemblies because the length of these features differed in the annotation files. The accuracy and quality of the annotation depend on whether a posterior manual validation of structures and 
functions is performed $[42,43]$. An example for a striking difference in the coding sequence between both annotations is DGAT1, a gene that harbours a missense variant (p.Ala232Lys) with a large impact on dairy traits [36]. Our GWAS identified a QTL for dairy traits at chromosome 14 in both assemblies. The QTL encompassed DGAT1 using the ARS-UCD1.2 annotation. However, $D G A T 1$ was not annotated at the corresponding sequence of the UOA_Angus_1 assembly. Given the manual curation efforts of the ARS-UCD1.2 annotation in contrast to the mere computational-based inference of annotations for UOA_Angus_1 from the Ensembl database, we suspect that the latter produces more erroneous annotations [43]. In fact, the ARS-UCD1.2 assembly is currently the widely accepted and universally applied bovine reference genome $[44,45]$. It is very unlikely that this will change soon because besides the completeness and continuity of the reference assembly, its functional annotation is crucial for downstream analyses. While tools exist to lift physical coordinates from one genomic context to another based on flanking sequences, this approach is cumbersome. Consequently, errors and gaps in the functional annotations of bovine reference-quality assemblies other than ARS-UCD1.2 are a major obstacle to switch references. The application of an augmented reference genome that contains ARS-UCD1.2 and its functional annotations as backbone as well as variants detected in other assemblies might solve such problems [12, 46].

We applied the composite likelihood ratio test to detect alleles that are either close to fixation or already reached fixation using genotypes obtained from both references. Supplying information about ancestral and derived alleles to the composite likelihood ratio test is required to determine which allele has been under selection and increases the statistical power to detect signatures of selection $[34,47]$. Although we were unable to differentiate between ancestral and derived alleles, we identified strong signatures of selection from both assemblies at regions encompassing genes that were previously detected in different cattle breeds including BSW [48-50]. However, quantifying the overlap between the signatures of selection detected in our and previous studies is not readily possible. First, a resource like AnimalQTLdb [51] that would allow for a systematic assessment of signatures of selection across studies does not exist. Second, differences in marker density and parameter settings (e.g., folded $v s$. unfolded site frequency spectrum) may affect the mapping precision and preclude an immediate comparison between studies. Third, the use of different assemblies, as it was the case in our study, results in coordinates that need to be lifted from one to another assembly. By visually inspecting the genes encompassed by the signatures of selection and manually lifting coordinates from ARS-UCD1.2 to UOA_Angus_1, we were able to confirm that the signatures of selection at chromosome 6 encompassing the NCAPG and on chromosome 5 upstream KITLG were indeed identical between both assemblies and detected previously in BSW cattle [50, 52]. This finding suggests that plausible signatures of selection can be identified using folded site frequency spectrum. However, we also detected signatures of selection that did not overlap between both assemblies. For instance, a strong selective sweep on chromosome 13 was only detected using the ARS-UCD1.2 assembly, while a putative sweep on chromosome 22 was only detected using the UOA_Angus_1 assembly. These differences were unexpected because the two assemblies were constructed from breeds that diverged relatively recent. In fact, Hereford and Angus are both taurine beef breeds that originate from Great Britain and phylogenetic analyses suggest that they are closely related [39]. The BSW cattle breed is also a taurine breed of European ancestry. When the BSW samples were aligned to the ARS-UCD1.2 assembly, the chromosome 13 region harbouring the signature of selection was depleted for variation, suggesting that the selected allele(s) already reached fixation. In fact, we observed many variants that were fixed for the alternate allele within the top windows at chromosome 13 . These variants were absent when the sequencing data were aligned to UOA_Angus_1, because their alternate alleles in ARS-UCD1.2 correspond to reference alleles in UOA_Angus_1. Thus, our findings suggest that detecting selective sweeps that already reached fixation with the composite likelihood ratio test depends on the relationship between the study population and the reference genome if a folded site frequency spectrum is used. The CLR test would reveal the same regions from both assemblies if only segregating sites are considered for the analysis. However, restricting the analysis to segregating sites bears a risk of missing sweeps that already reached fixation.

To our knowledge, a quantitative assessment of differences arising from the use of different reference genomes had only been performed in humans at a single nucleotide variant (SNV) level [25, 38]. Recently, Low et al. [17] mapped 38 cattle samples from 7 breeds against the Brahman and Angus assemblies to detect larger structural variants that may be involved in the adaptability of indicine cattle to harsh environments. We considered 161 BSW cattle for a thorough characterization of reference-guided analyses from two assemblies. As such an evaluation may be regularly performed in the future for many species, we developed a workflow that can be adapted and reused for varies breeds, populations and species [53]. In fact, our evaluation is the first to compare sequence variant discovery from primary and haplotype-resolved assemblies. Therefore, our findings also show that haplotyperesolved reference-quality assemblies may readily serve as 
reference genomes for linear read mapping and variant genotyping.

\section{Conclusions}

Our results suggest that both the ARS-UCD1.2 and UOA_Angus_1 assembly are suitable for reference-guided genome analyses in BSW cattle. The choice of the reference may have a large impact on detecting signatures of selection that already reached fixation. Furthermore, curation of the reference genomes is required to improve the characterisation of functional elements. The workflow herein developed is a starting point for a comprehensive comparison of the impact of reference genomes on genomic analyses in various breeds, populations and species.

\section{Methods}

\section{Data availability and code reproducibility}

Short paired-end whole-genome sequencing reads of 161 BSW cattle were considered for our analyses. Accession numbers for all animals are available in the Supplementary File 1: Table S1.

In order to investigate the effect of different assemblies on downstream analyses, we considered the current bovine Hereford-based reference genome (ARS-UCD12) [20] and an Angus-based reference-quality assembly (UOA_Angus_1) [17] that was generated from a F1 Angus $\mathrm{x}$ Brahman cross. The assemblies were downloaded from the public repositories of the NCBI (GCA_002263795.2, GCA_003369685.2). The UOA_Angus_1 assembly does not contain the $\mathrm{X}$ chromosomal sequence because it represents the paternal haplotype of a male animal. The ARS-UCD1.2 assembly was created from a female cow, thus does not contain a $\mathrm{Y}$ chromosomal sequence. For the sake of completeness, we expanded the ARS-UCD1.2 assembly with the $Y$ chromosomal sequence from Btau 5.0 and the UOA_Angus_1 assembly with the X chromosomal sequence from ARS-UCD1.2.

We compared the assemblies regarding mapping and variant calling, functional annotation, detection of signatures of selection, imputation and genome-wide association testing. Alignment, coverage, variant calling, imputation, annotation and analysis workflows were implemented as described below using Snakemake [54] (version 5.10.0). Python 3.7.4 has been used for running custom scripts as well as for submission and generation of Snakemake workflows.

Unless stated otherwise, the $\mathrm{R}$ (version 3.3.3) software environment and ggplot2 package (version 3.0.0) were used to create figures and perform statistical analyses. Paired t-test and Kruskal-Wallis rank sum test were applied to assess differences between assemblies for normal and not normal distributed values, respectively.

\section{Alignment quality and depth of coverage}

Quality assessment and control (removal of adapter sequences and reads and bases with low quality) of the raw sequencing data was carried out using the fastp software [55] (version 0.19.4) with default parameter settings. Reads were discarded when the phred-scaled quality was below 15 for more than $15 \%$ of the bases.

When necessary, the resulting FASTQ files were split into up to 13 read-group-specific FASTQ files to facilitate the read group aware processing of the data using gdc-fastq-splitter [56] (version 0.0.1). The filtered reads were subsequently aligned to both the ARS-UCD1.2 and UOA_Angus_1 assemblies (see above) using the MEMalgorithm of the Burrows-Wheeler Alignment (BWA) software [57, 58] (version 0.7.17) with option -M and - R to mark shorter split hits as secondary alignments and supply read group identifier and default values for all other parameters. Samblaster [59] (version 0.1.24) was used to mark duplicates in the SAM files, which were then converted into the binary format by using SAMtools [60] (version 1.6). Sambamba [61] (version 0.6.6) was used for coordinate-sorting (sort function) and to combine the read group-specific BAM files into sample-specific sorted BAM files. Duplicated reads and PCR duplicates of the merged and coordinate-sorted BAM files were marked using the MarkDuplicates module from Picard Tools [62] (version 2.18.17).

Uniquely mapped and properly paired reads that had mapping quality greater than 10 were obtained using SAMtools view -q 10 -F 1796. We considered a phredscaled mapping quality threshold of 10 to retain only reads (referred to as high-quality reads) that qualify for variant genotyping according to best practice guidelines of the GATK $[28,29]$.

The mosdepth software [63] (version 0.2.2) was used to extract the number of reads that covered a genomic position in order to obtain the average coverage per sample and chromosome. We considered only high-quality reads (by excluding reads with mapping quality $<10$ and SAM flag 1796).

\section{Sequence variant genotyping and variant statistics}

We used the BaseRecalibrator module of the Genome Analysis Toolkit (GATK - version 4.1.4.1) [64, 65] to adjust the base quality scores using 115,815,241 (ARSUCD1.2) and 87,710,119 (UOA_Angus_1) unique positions from the Bovine dbSNP version 150, as known variants. To obtain the coordinates of known sites for the UOA_Angus_1 assembly, we used liftover coordinates obtained from the mapping of 120 bases flanking the known ARS-UCD1.2 positions to UOA_Angus_1 using the MEM-approach of BWA (see above) with option $-\mathrm{k} 120$ to consider only full-length matches. To discover and genotype variants from the recalibrated BAM 
files, we used the GATK according to the best practice guidelines $[28,29]$. The GATK HaplotypeCaller module was run to produce gVCF (genomic Variant Call Format) files. The gVCF files were then consolidated using GenomicsDBImport and passed to the GenotypeGVCFs module to genotype polymorphic SNP and INDELs. We applied the VariantFiltration module for site-level filtration with the following recommended thresholds to retain high-quality SNP and INDELs: QualByDepth (QD) > 2.0, Qual $>30$, Strand Odds Ratio (SOR) $<3.0$, FisherStrand (FS) <60.0, RMSMappingQuality (MQ) > 40.0, MappingQualityRankSumTest (MQRankSum) $>12.5$, ReadPosRankSumTest (ReadPosRankSum) $>8.0$ for SNPs, and (QD) $>2.0$, Qual $>30$, Strand Odds Ratio (SOR) $<10.0$, FisherStrand (FS) $<200.0$, ReadPosRankSumTest (ReadPosRankSum) $>-20.0$ for INDELs. Only variants with a genotyping rate of $50 \%$ or higher (this is, minimum of 161 alleles - AN) were considered. Variants not meeting all the criteria were discarded.

Beagle [30] (version 4.1) haplotype phasing and imputation was run to improve the raw genotype calls and impute missing genotypes. The genotype likelihood $(\mathrm{gl})$ mode was applied in order to infer missing and adjust existing genotypes based on the phred-scaled likelihoods of all other non-missing genotypes.

Alternate allele frequency was calculated using the 'keep-allele-order -freq flags with PLINK 1.9 [66] and non-segregating variants were subsequently filtered out from the imputed VCF file with the option '-mac 1 remove-filtered-all from VCFtools [67]. Biallelic variants have been retrieved by using the filter '-min-alleles 2 -max-alleles 2 ' with VCFtools. Index and stats for the relevant VCF files were generated through tabix [68], VCFtools and BCFtools [69], respectively. Per-sample stats were obtained by adding the '- $v$ ' flag when generating the stats with VCFtools. Observed genotypes were tested for deviation from Hardy-Weinberg proportions using the '-hwe 10e-8' and '-hardy -recode' flags with PLINK 1.9 [66]. Transition and transversion ratio of SNPs were calculated via VCFtools.

\section{Functional annotation of polymorphic sites}

Functional consequences of high-quality and non-fixed SNPs and INDELs were predicted according to the Ensembl (release 101) annotation of the bovine genome assembly ARS-UCD1.2 and UOA_Angus_1, respectively, using the Ensembl Variant Effect Predictor tool (VEP version 91.3) [70] with default parameters and '-hgvs -symbol nomenclature. The classification of variants according to sequence ontology terms and the prediction of putative impacts on protein function followed Ensembl guidelines. Basic statistics of the annotation were calculated using AGAT [71] (version v0.5.1).

\section{Signatures of selection}

Signatures of recent selection were identified using the composite likelihood ratio (CLR) approach implemented in Sweepfinder2 [72]. We considered 19,370,683 (ARSUCD1.2) and 19,255,155 (UOA_Angus_1) biallelic SNP (segregating sites and SNP that were fixed for the nonreference allele) to calculate the CLR in $20 \mathrm{~Kb}$ windows with pre-computed empirical alternate allele frequency. The top $0.1 \%$ windows were considered as putative selective sweeps. Adjacent top $0.1 \%$ windows were merged into regions. The gene content of the regions was determined according to the annotations from Ensembl (release 101) using BEDTools [73].

\section{Dot plots}

To identify sequence similarities and dissimilarities between the two assemblies, we inspected chromosome wise dot plots of pair-wise sequence alignments using LASTZ [74] (v1.04.03) with the options '-notransition -nogapped -step $=20$-exact $=50^{\circ}$ using repeat-masked assemblies which we downloaded from Ensembl (release 101).

\section{Imputation}

Microarray-derived SNP genotypes were available for 30,499 BSW cattle typed on seven low-density (20k150k) and one high-density chip (Illumina BovineHD; 777k). Coordinates of the SNP were originally determined according to the ARS-UCD1.2 build. To remap the SNP to the UOA_Angus_1 assembly, we used liftover coordinates obtained from the mapping of 120 bases flanking the BovineHD probes to the UOA_Angus_1 assembly using the MEM algorithm of BWA [57, 58] with option $-\mathrm{k} 120$ to consider only full-length matches. Both the original and the remapped genotype data were imputed (separately) to the whole genome sequence level using a stepwise approach with reference panels aligned to the respective genome assemblies. First, genotypes for all animals typed at low density were imputed to higher density ( $\mathrm{N}=683,752$ (ARS-UCD1.2) and 622,699 (UOA_Angus_1) SNP) using 1,166 reference animals with BovineHD-derived genotypes. In a second step, the partially imputed high-density genotypes were imputed to the sequence level using a reference panel of 161 sequenced animals. Both steps of imputation were carried out with Beagle 5.1 [75]. Variants with MAC $>3$ (or) deviating significantly from HardyWeinberg proportions $\left(\mathrm{P}<10^{-6}\right)$, (or) with imputation accuracy (Beagle $\mathrm{R}^{2}$ ) less than 0.5 were filtered out. The imputed data with variants aligned to the ARSUCD1.2 and UOA_Angus_1 assembly respectively, contained genotypes at 12,761,165 and 12,602,069 sequence variants. 


\section{Genome-wide association testing and estimation of genomic heritability}

We tested the association between phenotypes in the form of de-regressed proofs for six traits and sequence variants in between 11,294 and 12,434 BSW cattle. We considered phenotypes for stature $(\mathrm{N}=11,294)$, milk yield $(\mathrm{N}=13,388)$, protein yield $(\mathrm{N}=12,392)$, fat yield $(\mathrm{N}=12,388)$, protein content $(\mathrm{N}=12,439)$, and fat content $(\mathrm{N}=12,434)$. The SNP-based association study was carried out using a linear mixed model implemented with the MLMA-approach of the GCTA software package [76]. The model included a genomic relationship matrix built from 560,777 autosomal SNPs that were typed on the BovineHD chip (positions mapped according to ARS-UCD1.2) and four principal components to account for relatedness and population stratification. The genomic heritability was estimated for the six traits using the genomic restricted maximum likelihood (GREML) approach implemented in GCTA [76]. Therefore, we used genomic relationship matrices (GRM) that were built from all imputed autosomal sequence variants. We also partitioned the genomic heritability onto individual autosomes using GRM built from variants of the respective autosomes.

\section{Abbreviations}

bp: Base pairs; BSW: Brown Swiss; CLR: Composite likelihood ratio; GATK: Genome analysis toolkit; GWAS: Genome-wide association study; $h^{2}$ : Heritability; INDELs: Insertions and deletions; Kb: Kilo base pairs; Mb: Mega base pairs; QTL: Quantitative trait locus; SNP: Single nucleotide polymorphism

\section{Supplementary Information}

The online version contains supplementary material available at https://doi.org/10.1186/s12864-021-07554-w.

Additional file 1: Table S1: BSW cattle IDs. Accession IDs of the 161 bovine samples used for our study.

Additional file 2: Table S2: Number of mapped reads contained in the original files but not considered for our study. Number of reads mapped to sexual chromosomes and to unplaced contigs for both assemblies. Low quality mapping includes the number of reads filtered out when considering only uniquely mapped properly paired reads with a mapping quality threshold of 10 . Sample-wise mean and standard deviation can be found between parentheses. The length of the sexual chromosomes and unplaced contigs is also included.

Additional file 3: Table S3: Number of variants during the different filtering steps: from original variants to high-quality and non-fixed variants. Original variants are considered as the raw variants retrieved from GATK. Low quality variants are discarded during hard-filtering and fixed variants are identified when the minor allele count (MAC) is set to 1 in VCFtools. The percentage of variants to the original variants before hard-filtering are in parentheses.

Additional file 4: Figure S1: Variant density of the autosomes for both assemblies. Number of variants detected per kilo base pair (Kb) along autosomal sequences of 161 BSW samples when aligned to the ARS-UCD1.2 (blue) and UOA_Angus_1 (orange) assembly.

Additional file 5: Figure S2: Density of variants across chromosomes 13 and 23. The number of variants is shown within non-overlapping windows of $10 \mathrm{~Kb}$ for chromosome 13 (A) and 23 (B). The $x$-axis indicates the length of the chromosome (in Mb). The number of variants within each $10 \mathrm{~Kb}$ window is shown on the $y$-axis. Assembly ARS-UCD1.2 is displayed in the top panel (blue) and assembly UOA_Angus_1 is displayed as a mirror image in the bottom panel (orange).
Additional file 6: Table S4: Density of high-quality and non-fixed variants per Kb along the autosomal genome. Unlike Table 3 in the main text, densities are calculated here when chromosome 12 is not considered Additional file 7: Table S5: Number and percentage of multiallelic variants. Percentage of multiallelic variants is obtained from the division of multiallelic variants to non-fixed high-quality variants. Multiallelic variants are identified when the '-min-alleles 2 -max-alleles 2 ' flag is set in VCFtools. Alleles not in Hardy-Weinberg proportions are the number of variants with $P$-value below the threshold of 10-8 when testing for Hardy-Weinberg proportions with PLINK. Percentages are between parentheses.

Additional file 8: Figure S3: Density of variants deviating from Hardy-Weinberg proportion for chromosome 12. The number of variants differing from Hardy-Weinberg proportion are plotted as non-overlapping windows of $10 \mathrm{~Kb}$ along the autosomal sequence. The $y$-axis relates the variant density, number of variants per $100 \mathrm{~Kb}$, for each 10-Kb-windows.

Additional file 9: Table S6: Summary of the annotated sequence ontology classes of SNPS and INDELs. SO terms are described by Ensembl. Total number of high-quality and non-fixed annotated SNPS and INDELs for both assemblies that were annotated using the release 101 annotation files with VEP tool.

Additional file 10: Table S7: Candidate selection signatures detected using ARS-UCD1.2 as reference. Genomic coordinates, CLR values, $P$-values and encompassed genes for 40 candidate selection signatures.

Additional file 11: Table S8: Candidate selection signatures detected using UOA_Angus_1 as reference. Genomic coordinates, CLR values, $P$-values and encompassed genes for 33 candidate selection signatures.

Additional file 12: Figure S4: Selective sweeps on chromosome 13. Chromosome 13 region in ARS-UCD1.2 from 10,501,688 - 12,506,844 Mb and corresponding region on UOA_Angus_1 between 71,231,671 -

$73,018,009 \mathrm{Mb}$ with highlighted six selective sweep region from 11.5 Mb to $12 \mathrm{Mb}$. (A) Dot plot between the two assemblies, (B) SNP density per Kb (red line represents the average SNP density/chromosome), (C) Standardized coverage per $0.5 \mathrm{~Kb}$, (D) Alternate allele frequency of each SNP (each dot is per SNP).

Additional file 13: Figure S5: Selective sweeps on chromosome 22. Chromosome 22 region in ARS-UCD1.2 from 11,928,425-12,925,926 Mb and corresponding region on UOA_Angus_1 between 12,003,259 -

$13,000,720 \mathrm{Mb}$ with highlighted two selective sweep region. (A) Dot plot between the two assemblies, (B) SNP density per Kb (red line represents the average SNP density/chromosome), (C) Standardized coverage per 0.5 $\mathrm{Kb}$, (D) Alternate allele frequency of each SNP (where each dot is per SNP).

Additional file 14: Figure S6: Genome Wide Association Study (GWAS). Manhattan plots showing association of sequence variants - imputed using ARS-UCD1.2 (blue and grey) and UOA_Angus_1 (orange and grey) - with fat yield (A), protein yield (B) and stature (C).

\section{Acknowledgements}

We thank the Functional Genomics Center Zurich for generating DNA sequencing data. We thank the Arbeitsgemeinschaft Deutsches Braunvieh and the Arbeitsgemeinschaft Süddeutscher Rinderzüchter und Besamungsorganisationen e.V. (ASR) for granting access to whole-genome sequencing data of important key ancestor animals.

\section{Authors' contributions}

Generated the data: HP, RF; Conceived and designed the experiments: ALV, HP; Analyzed the data: ALV, MB, NKK, HP; Wrote the manuscript: ALV, MB, NKK, HP. All authors have agreed on the content of the manuscript.

\section{Funding}

This study was supported by a grant from the Swiss National Science Foundation (310030_185229) and the European Union's Horizon 2020 research and innovation programme under Grant Agreement No 815668 (BovReg). The funding bodies were not involved in the design of the study and collection, analysis, and interpretation of data and in writing the manuscript.

\section{Availability of data and materials}

Accession numbers for all animals are available in the Supplementary File 1: Table S1. All workflows and scripts used to produce the results are available at the ETH Animal Genomics Github repository [53]. 


\section{Declarations}

\section{Ethics approval and consent to participate}

\author{
Not applicable.
}

\section{Consent for publication}

Not applicable.

\section{Competing interests}

$\mathrm{HP}$ is a member of the editorial board of BMC Genomics. All other authors declare that they have no competing interests. No financial conflict of interest exists for any of the authors in the manuscript.

\section{Author details}

${ }^{1}$ Animal Genomics, ETH Zürich, 8315 Lindau, Switzerland. ${ }^{2}$ Chair of Animal Breeding, TU München, 85354 Freising-Weihenstephan, Germany.

\section{Received: 15 January 2021 Accepted: 22 March 2021}

\section{Published online: 19 May 2021}

\section{References}

1. Zhao H, Sun Z, Wang J, Huang H, Kocher JP, Wang L. CrossMap: A versatile tool for coordinate conversion between genome assemblies. Bioinformatics. 2014;30(7):1006-7. https://doi.org/10.1093/ bioinformatics/btt730.

2. Schook LB, Beever JE, Rogers J, Humphray S, Archibald A, Chardon P, Milan D, Rohrer G, Eversole K. Swine Genome Sequencing Consortium (SGSC): A strategic roadmap for sequencing the pig genome. In: Comp Funct Genom; 2005. p. 251-5. https://doi.org/10.1002/cfg.479.

3. The Bovine Genome Sequencing and Analysis Consortium, Elsik CG, Tellam RL, Worley KC, Gibbs RA, Muzny DM, Weinstock GM, Adelson DL, Eichler EE, Elnitski L, Guigó R, Hamernik DL, Kappes SM, Lewin HA, Lynn DJ, Nicholas FW, Reymond A, Rijnkels M, Skow LC, Zdobnov EM, Schook L, Womack J, Alioto T, Antonarakis SE, Astashyn A, Chappie CE, Chen HC, Chrast J, Câmara F, Ermolaeva O, Henrichsen CN, Hlavina W, Kapustin Y, Kiryutin B, Kitts P, Kokocinski F, Landrum M, Maglott D, Pruitt K, Sapojnikov V, Searle SM, Solovyev V, Souvorov A, Ucla C, Wyss C, Anzola JM, Gerlach D, Elhaik E, Graur D, Reese JT, Edgar RC, McEwan JC, Payne GM, Raison JM, Junier T, Kriventseva EV, Eyras E, Plass M, Donthu R, Larkin DM, Reecy J, Yang MQ, Chen L, Cheng Z, Chitko-McKown CG, Liu GE, Matukumalli LK, Song J, Zhu B, Bradley DG, Brinkman FSL, Lau LPL, Whiteside MD, Walker A, Wheeler TT, Casey T, German JB, Lemay DG, Maqbool NJ, Molenaar AJ, Seo S, Stothard P, Baldwin $C L$, Baxter R, Brinkmeyer-Larigford CL, Brown WC, Childers $C P$, Connelley T, Ellis SA, FritzK, Glass EJ, Herzig CTA, Livanainen A, Lahmers KK, Bennett AK, Dickens CM, Gilbert JGR, Hagen DE, Salih H, Aerts J, Caetano AR, Dalrymple B, Garcia JF, Gill CA, Hiendleder SG, Memili E, Spurlock D, Williams JL, Alexander L, Brownstein MJ, Guan L, Holt RA, Jones SJM, Marra MA, Moore R, Moore SS, Roberts A, Taniguchi M, Waterman RC, Chacko J, Chandrabose MM, Cree A, Dao MD, Dinh HH, Gabisi RA, Hines S, Hume J, Jhangiani SN, Joshi V, Kovar CL, Lewis LR, Liu YS, Lopez J, Morgan MB, Nguyen NB, Okwuonu GO, Ruiz SJ, Santibanez J, Wright RA, Buhay C, Ding Y, Dugan-Rocha S, Herdandez J, Holder M, Sabo A, Egan A, Goodell J, Wilczek-Boney K, Fowler GR, Hitchens ME, Lozado RJ, Moen C, Steffen D, Warren JT, Zhang J, Chiu R, Schein JE, Durbin KJ, Havlak P, Jiang H, Liu Y, Qin X, Ren Y, Shen Y, Song H, Bell SN, Davis C, Johnson AJ, Lee S, Nazareth LV, Patel BM, Pu LL, Vattathil S, Williams RL, Curry S, Hamilton C, Sodergren E, Wheeler DA, Barris W, Bennett GL, Eggen A, Green RD, Harhay GP, Hobbs M, Jann O, Keele JW, Kent MP, Lien S, McKay SD, McWilliam S, Ratnakumar A, Schnabel RD, Smith T, Snelling WM, Sonstegard TS, Stone RT, Sugimoto Y, Takasuga A, Taylor JF, Van Tassell CP, MacNeil MD, Abatepaulo ARR, Abbey CA, Ahola V, Almeida LG, Amadio AF, Anatriello E, Bahadue SM, Biase FH, Boldt CR, Carroll JA, Carvalho WA, Cervelatti EP, Chacko E, Chapin JE, Cheng Y, Choi J, Colley AJ, DeCampos TA, De Donato M, De Miranda Santos IKF, De Oliveira CJF, Deobald H, Devinoy E, Donohue KE, Dove P, Eberlein A, Fitzsimmons C. The genome sequence of taurine cattle: A window to ruminant biology and evolution. Science. 2009;324(5926):522-8. https://doi.org/10.1126/science.1169588.

4. International Chicken Genome Sequencing Consortium. Sequence and comparative analysis of the chicken genome provide unique perspectives on vertebrate evolution. Nature. 2004;432:695-716. https:// doi.org/10.1038/nature03154.

5. Tellam RL, Lemay DG, Van Tassell CP, Lewin HA, Worley KC, Elsik CG. Unlocking the bovine genome. BMC Genomics. 2009;10:193. https://doi. org/10.1186/1471-2164-10-193.

6. The Bovine HapMap Consortium, Eichler EE, Guigó R, Hamernik DL, Kappes SM, Lewin HA, Lynn DJ, Nicholas FW, Reymond A, Rijnkels M, Skow LC, Zdobnov EM, Schook L, Womack J, Alioto T, Antonarakis SE, Astashyn A, Chappie CE, Chen HC, Chrast J, Câmara F, Ermolaeva O, Henrichsen CN, Hlavina W, Kapustin Y, Kiryutin B, Kitts P, Kokocinski F, Landrum M, Maglott D, Pruitt K, Sapojnikov V, Searle SM, Solovyev V, Souvorov A, Ucla C, Wyss C, Anzola JM, Gerlach D, Elhaik E, Graur D, Reese JT, Edgar RC, McEwan JC, Payne GM, Raison JM, Junier T, Kriventseva EV, Eyras E, Plass M, Donthu R, Larkin DM, Reecy J, Yang MQ, Chen L, Cheng Z, Chitko-McKown CG, Liu GE, Matukumalli LK, Song J, Zhu B, Bradley DG, Brinkman FSL, Lau LPL, Whiteside MD, Walker A, Wheeler TT, Casey T, German JB, Lemay DG, Maqbool NJ, Molenaar AJ, Seo S, Stothard P, Baldwin CL, Baxter R, Brinkmeyer-Larigford CL, Brown WC, Childers CP, Connelley T, Ellis SA, Fritz K, Glass EJ, Herzig CTA, Livanainen A, Lahmers KK, Bennett AK, Dickens CM, Gilbert JGR, Hagen DE, Salih H, Aerts J, Caetano AR, Dalrymple B, Garcia JF, Gill CA, Hiendleder SG, Memili E, Spurlock D, Williams JL, Alexander L, Brownstein MJ, Guan L, Holt RA, Jones SJM, Marra MA, Moore R, Moore SS, Roberts A, Taniguchi M, Waterman RC, Chacko J, Chandrabose MM, Cree A, Dao MD, Dinh HH, Gabisi RA, Hines S, Hume J, Jhangiani SN, Joshi V, Kovar CL, Lewis LR, Liu YS, Lopez J, Morgan MB, Nguyen NB, Okwuonu GO, Ruiz SJ, Santibanez J, Wright RA, Buhay C, Ding Y, Dugan-Rocha S, Herdandez J, Holder M, Sabo A, Egan A, Goodell J, Wilczek-Boney K, Fowler GR, Hitchens ME, Lozado RJ, Moen C, Steffen D, Warren JT, Zhang J, Chiu R, Schein JE, Durbin KJ, Havlak P, Jiang H, Liu Y, Qin X, Ren Y, Shen Y, Song H, Bell SN, Davis C, Johnson AJ, Lee $S$, Nazareth LV, Patel BM, Pu LL, Vattathil S, Williams RL, Curry S, Hamilton C, Sodergren E, Wheeler DA, Barris W, Bennett GL, Eggen A, Green RD, Harhay GP, Hobbs M, Jann O, Keele JW, Kent MP, Lien S, McKay SD, McWilliam S, Ratnakumar A, Schnabel RD, Smith T, Snelling WM, Sonstegard TS, Stone RT, Sugimoto Y, Takasuga A, Taylor JF, Van Tassell CP, MacNeil MD, Abatepaulo ARR, Abbey CA, Ahola V, Almeida LG, Amadio AF, Anatriello E, Bahadue SM, Biase FH, Boldt CR, Carroll JA, Carvalho WA, Cervelatti EP, Chacko E, Chapin JE, Cheng Y, Choi J, Colley AJ, DeCampos TA, De Donato M, De Miranda Santos IKF, De Oliveira CJF, Deobald H, Devinoy E, Donohue KE, Dove P, Eberlein A Fitzsimmons CJ, Franzin AM, Garcia GR, Genini S, Gladney CJ, Grant JR, Greaser ML, Green JA, Hadsell DL, Hakimov H. Genome-Wide Survey of SNP Variation Uncovers the Genetic Structure of Cattle Breeds. Science. 2009;324(5926):522-8. https://doi.org/10.1126/science.1169588.

7. Jansen S, Aigner B, Pausch H, Wysocki M, Eck S, Benet-Pagès A, Graf E, Wieland T, Strom TM, Meitinger T, Fries R. Assessment of the genomic variation in a cattle population by re-sequencing of key animals at low to medium coverage. BMC Genomics. 2013;14(1):. https://doi.org/10.1186/ 1471-2164-14-446.

8. Daetwyler HD, Capitan A, Pausch H, Stothard P, Van Binsbergen R, Brøndum RF, Liao X, Djari A, Rodriguez SC, Grohs C, Esquerré D, Bouchez O, Rossignol MN, Klopp C, Rocha D, Fritz S, Eggen A, Bowman PJ, Coote D, Chamberlain AJ, Anderson C, Vantassell CP, Hulsegge I, Goddard ME, Guldbrandtsen B, Lund MS, Veerkamp RF, Boichard DA, Fries R, Hayes BJ. Whole-genome sequencing of 234 bulls facilitates mapping of monogenic and complex traits in cattle. Nat Genet. 2014:46(8):858-65. https://doi.org/10.1038/ng.3034.

9. Koufariotis L, Hayes BJ, Kelly M, Burns BM, Lyons R, Stothard P, Chamberlain AJ, Moore S. Sequencing the mosaic genome of Brahman cattle identifies historic and recent introgression including polled. Sci Rep. 2018;8(1):. https://doi.org/10.1038/s41598-018-35698-5.

10. Pritt J, Chen NC, Langmead B. FORGe: Prioritizing variants for graph genomes. Genome Biol. 2018;19(1):220. https://doi.org/10.1186/s13059018-1595-x.

11. Crysnanto D, Wurmser $C$, Pausch $H$. Accurate sequence variant genotyping in cattle using variation-aware genome graphs. Genet Sel Evol. 2019;51(1):21. https://doi.org/10.1186/s12711-019-0462-x.

12. Crysnanto D, Pausch H. Bovine breed-specific augmented reference graphs facilitate accurate sequence read mapping and unbiased variant discovery. Genome Biol. 2020;21(184). https://doi.org/10.1186/s13059020-02105-0. 
13. Ballouz S, Dobin A, Gillis JA. Is it time to change the reference genome? Genome Biol. 2019;20(1):1-9. https://doi.org/10.1186/s13059-019-1774-4.

14. Eid J. Real-time DNA sequencing from single polymerase molecules. Science. 2009;323(5910):130-3. https://doi.org/10.1126/science.1162986.

15. Mikheyev AS, Tin MMY. A first look at the Oxford Nanopore MinION sequencer. Mol Ecol Resour. 2014;14(6):1097-102. https://doi.org/10. 1111/1755-0998.12324.

16. van Dijk Erwin L, Jaszczyszyn Y, Naquin D, Thermes C. The Third Revolution in Sequencing Technology. Trends Genet. 2018;34(9):666-81. https://doi.org/10.1016/j.tig.2018.05.008.

17. Low WY, Tearle R, Liu R, Koren S, Rhie A, Bickhart DM, Rosen BD, Kronenberg ZN, Kingan SB, Tseng E, Thibaud-Nissen F, Martin FJ, Billis K, Ghurye J, Hastie AR, Lee J, Pang AWC, Heaton MP, Phillippy AM, Hiendleder S, Smith TPL, Williams JL. Haplotype-resolved genomes provide insights into structural variation and gene content in Angus and Brahman cattle. Nat Commun. 2020;11(1):. https://doi.org/10.1038/ s41467-020-15848-y.

18. Cheng H, Concepcion GT, Feng X, Zhang H, Li H. Haplotype-resolved de novo assembly with phased assembly graphs. 2020. http://arxiv.org/abs/ 2008.01237. Accessed 06 Apr 2021.

19. Koren S, Rhie A, Walenz BP, Dilthey AT, Bickhart DM, Kingan SB, Hiendleder S, Williams JL, Smith TPL, Phillippy AM. De novo assembly of haplotype-resolved genomes with trio binning. Nat Biotechnol. 2018;36(12):1174-82. https://doi.org/10.1038/nbt.4277.

20. Rosen BD, Bickhart DM, Schnabel RD, Koren S, Elsik CG, Tseng E, Rowan TN, Low WY, Zimin A, Couldrey C, Hall R, Li W, Rhie A, Ghurye J, McKay SD, Thibaud-Nissen F, Hoffman J, Murdoch BM, Snelling WM, McDaneld TG, Hammond JA, Schwartz JC, Nandolo W, Hagen DE, Dreischer C, Schultheiss SJ, Schroeder SG, Phillippy AM, Cole JB, Van Tassell CP, Liu G, Smith TPL, Medrano JF. De novo assembly of the cattle reference genome with single-molecule sequencing. GigaScience. 2020;9(3):. https://doi.org/10.1093/gigascience/giaa021.

21. Rice ES, Koren S, Rhie A, Heaton MP, Kalbfleisch TS, Hardy T, Hackett PH, Bickhart DM, Rosen BD, Ley BV, Maurer NW, Green RE, Phillippy AM, Petersen JL, Smith TPL. Continuous chromosome-scale haplotypes assembled from a single interspecies $F 1$ hybrid of yak and cattle. GigaScience. 2020;9(4):1-9. https://doi.org/10.1093/gigascience/giaa029.

22. Sherman RM, Forman J, Antonescu V, Puiu D, Daya M, Rafaels N, Boorgula MP, Chavan S, Vergara C, Ortega VE, Levin AM, Eng C, Yazdanbakhsh M, Wilson JG, Marrugo J, Lange LA, Williams LK, Watson H, Ware LB, Olopade CO, Olopade O, Oliveira RR, Ober C, Nicolae DL, Meyers DA, Mayorga A, Knight-Madden J, Hartert T, Hansel NN, Foreman MG, Ford JG, Faruque MU, Dunston GM, Caraballo L, Burchard EG, Bleecker ER, Araujo MI, Herrera-Paz EF, Campbell M, Foster C, Taub MA, Beaty TH, Ruczinski I, Mathias RA, Barnes KC, Salzberg SL. Assembly of a pan-genome from deep sequencing of 910 humans of African descent. Nat Genet. 2019;51(1):30-5. https://doi.org/10.1038/s41588-018-0273-y.

23. Degner JF, Marioni JC, Pai AA, Pickrell JK, Nkadori E, Gilad Y, Pritchard JK. Effect of read-mapping biases on detecting allele-specific expression from RNA-sequencing data. Bioinformatics. 2009;25(24):3207-12. https:// doi.org/10.1093/bioinformatics/btp579.

24. Günther T, Nettelblad C. The presence and impact of reference bias on population genomic studies of prehistoric human populations. PLoS Genet. 2019;15(7):1008302. https://doi.org/10.1371/journal.pgen. 1008302.

25. Guo Y, Dai Y, Yu H, Zhao S, Samuels DC, Shyr Y. Improvements and impacts of GRCh38 human reference on high throughput sequencing data analysis. Genomics. 2017;109(2):83-90. https://doi.org/10.1016/j. ygeno.2017.01.005.

26. Leinonen $\mathrm{R}$, Sugawara $H$, Shumway $M$. The sequence read archive. Nucleic Acids Res. 2011;39(SUPPL. 1):19-21. https://doi.org/10.1093/nar/ gkq1019.

27. Leinonen R, Akhtar R, Birney E, Bower L, Cerdeno-Tárraga A, Cheng $Y$, Cleland I, Faruque N, Goodgame N, Gibson R, Hoad G, Jang M, Pakseresht N, Plaister S, Radhakrishnan R, Reddy K, Sobhany S, Hoopen PT, Vaughan R, Zalunin V, Cochrane G. The European nucleotide archive. Nucleic Acids Res. 2011;39(SUPPL. 1):28-31. https://doi.org/10.1093/nar/ gkq967.

28. Van der Auwera GA, Carneiro MO, Hartl C, Poplin R, del Angel G, Levy-Moonshine A, Jordan T, Shakir K, Roazen D, Thibault J, Banks E, Garimella KV, Altshuler D, Gabriel S, DePristo MA. From fastQ data to high-confidence variant calls: The genome analysis toolkit best practice pipeline. Curr Protoc Bioinforma. 2013;SUPL.43:1110. https://doi.org/10. 1002/0471250953.bi1110s43.

29. Broad_Institute. Germline short variant discovery (SNPs + Indels). 2021 https://gatk.broadinstitute.org/hc/en-us/articles/360035535932Germline-short-variant-discovery-SNPs-Indels-. Accessed 13 Gen 2021.

30. Browning BL, Browning SR. Genotype Imputation with Millions of Reference Samples. Am J Hum Genet. 2016;98(1):116-26. https://doi.org/ 10.1016/j.ajhg.2015.11.020.

31. Liu GE, Ventura M, Cellamare A, Chen L, Cheng Z, Zhu B, Li C, Song J, Eichler EE. Analysis of recent segmental duplications in the bovine genome. BMC Genomics. 2009;10:. https://doi.org/10.1186/1471-216410-571.

32. Bickhart DM, Hou Y, Schroeder SG, Alkan C, Cardone MF, Matukumalli LK, Song J, Schnabel RD, Ventura M, Taylor JF, Garcia JF, Van Tassell CP, Sonstegard TS, Eichler EE, Liu GE. Copy number variation of individual cattle genomes using next-generation sequencing. Genome Res. 2012;22(4):778-90. https://doi.org/10.1101/gr.133967.111.

33. Pausch $H$, MacLeod IM, Fries R, Emmerling R, Bowman PJ, Daetwyler HD, Goddard ME. Evaluation of the accuracy of imputed sequence variant genotypes and their utility for causal variant detection in cattle. Genet Sel Evol. 2017;49(1):. https://doi.org/10.1186/s12711-017-0301-X.

34. Nielsen R, Williamson S, Kim Y, Hubisz MJ, Clark AG, Bustamante C. Genomic scans for selective sweeps using SNP data. Genome Res. 2005;15(11):1566-75. https://doi.org/10.1101/gr.4252305.

35. Blott S, Kim J-J, Moisio S, Schmidt-Küntzel A, Cornet A, Berzi P, Cambisano N, Ford C, Grisart B, Johnson D, Karim L, Simon P, Snell R, Spelman R, Wong J, Vilkki J, Georges M, Farnir F, Coppieters W, Biosciences $V$. Molecular dissection of a quantitative trait locus: a phenylalanine-to-tyrosine substitution in the transmembrane domain of the bovine growth hormone receptor is associated with a major effect on milk yield and composition. Genetics. 2003;163(1):253-66.

36. Grisart B, Coppieters W, Farnir F, Karim L, Ford C, Berzi P, Cambisano N, Mni M, Reid S, Simon P, Spelman R, Georges M, Snell R. Positional candidate cloning of a QTL in dairy cattle: Identification of a missense mutation in the bovine DGAT1 gene with major effect on milk yield and composition. Genome Res. 2002;12(2):222-31. https://doi.org/10.1101/gr. 224202.

37. Asalone KC, Ryan KM, Yamadi M, Cohen AL, Farmer WG, George DJ, Joppert C, Kim K, Mughal MF, Said R, Toksoz-Exley M, Bisk E, Bracht JR. Regional sequence expansion or collapse in heterozygous genome assemblies. PLoS Comput Biol. 2020;16(7):1008104. https://doi.org/10. 1371/journal.pcbi.1008104.

38. Pan B, Kusko R, Xiao W, Zheng Y, Liu Z, Xiao C, Sakkiah S, Guo W, Gong P, Zhang C, Ge W, Shi L, Tong W, Hong H. Similarities and differences between variants called with human reference genome HG19 or HG38. BMC Bioinformatics. 2019;20:. https://doi.org/10.1186/s12859-019-2620-0.

39. Decker JE, McKay SD, Rolf MM, Kim JW, Molina Alcalá A, Sonstegard TS, Hanotte O, Götherström A, Seabury CM, Praharani L, Babar ME, Correia de Almeida Regitano L, Yildiz MA, Heaton MP, Liu WS, Lei CZ, Reecy JM, Saif-Ur-Rehman M, Schnabel RD, Taylor JF. Worldwide Patterns of Ancestry, Divergence, and Admixture in Domesticated Cattle. PLoS Genet. 2014;10(3):. https://doi.org/10.1371/journal.pgen.1004254.

40. Bohling J. Evaluating the effect of reference genome divergence on the analysis of empirical RADseq datasets. Ecol Evol. 2020;10(14):7585-601. https://doi.org/10.1002/ece3.6483.

41. Watson M, Warr A. Errors in long-read assemblies can critically affect protein prediction. Nat Biotechnol. 2019;37(2):124-6. https://doi.org/10. 1038/s41587-018-0004-z.

42. Haridas S, Salamov A, Grigoriev IV. Fungal genome annotation. In: Methods in Molecular Biology, vol. 1775. School of Life and Medical Sciences University of Hertfordshire Hatfield, Hertfordshire, AL10 9AB, UK: Humana Press Inc.; 2018. p. 171-84. https://doi.org/10.1007/978-1-49397804-5_15.

43. McDonnell E, Strasser K, Tsang A. Manual gene curation and functional annotation. In: Methods in Molecular Biology. School of Life and Medical Sciences University of Hertfordshire Hatfield, Hertfordshire, AL10 9AB, UK: Humana Press Inc.; 2018. p. 185-208. https://doi.org/10.1007/978-14939-7804-5_16.

44. Andersson L, Archibald AL, Bottema CD, Brauning R, Burgess SC, Burt DW, Casas E, Cheng HH, Clarke L, Couldrey C, Dalrymple BP, Elsik CG, 
Foissac S, Giuffra E, Groenen MA, Hayes BJ, Huang LSS, Khatib H, Kijas JW, Kim H, Lunney JK, McCarthy FM, McEwan JC, Moore S, Nanduri B, Notredame C, Palti Y, Plastow GS, Reecy JM, Rohrer GA, Sarropoulou E, Schmidt CJ, Silverstein J, Tellam RL, Tixier-Boichard M, Tosser-Klopp G, Tuggle CK, Vilkki J, White SN, Zhao S, Zhou H. Coordinated international action to accelerate genome-to-phenome with FAANG, the Functional Annotation of Animal Genomes project. Genome Biol. 2015;16(1):57. https://doi.org/10.1186/s13059-015-0622-4.

45. Clark EL, Archibald AL, Daetwyler HD, Groenen MAM, Harrison PW, Houston RD, Kühn C, Lien S, Macqueen DJ, Reecy JM, Robledo D, Watson M, Tuggle CK, Giuffra E. From FAANG to fork: application of highly annotated genomes to improve farmed animal production. Genome Biol. 2020;21 (1):285. https://doi.org/10.1186/s13059-020-02197-8.

46. Crysnanto D, Leonard AS, Fang Z-H, Pausch H. Novel functional sequences uncovered through a bovine multi-assembly graph. BioRxiv. 2021. https://doi.org/10.1101/2021.01.08.425845.

47. Huber CD, DeGiorgio M, Hellmann I, Nielsen R. Detecting recent selective sweeps while controlling for mutation rate and background selection. Mol Ecol. 2016;25(1):142-56. https://doi.org/10.1111/mec.13351.

48. Rothammer S, Seichter D, Förster M, Medugorac I. A genome-wide scan for signatures of differential artificial selection in ten cattle breeds. BMC Genomics. 2013;14(908):1. https://doi.org/10.1186/1471-2164-14-908.

49. Xu L, Bickhart DM, Cole JB, Schroeder SG, Song J, Van Tassell CP, Sonstegard TS, Liu GE. Genomic signatures reveal new evidences for selection of important traits in domestic cattle. Mol Biol Evol. 2015;32(3): 711-25. https://doi.org/10.1093/molbev/msu333.

50. Bhati M, Kadri NK, Crysnanto D, Pausch H. Assessing genomic diversity and signatures of selection in Original Braunvieh cattle using whole-genome sequencing data. BMC Genomics. 2020;21(1):. https://doi. org/10.1186/s12864-020-6446-y.

51. Hu Z, Park C, Reecy J. Building a livestock genetic and genomic information knowledgebase through integrative developments of Animal QTLdb and CorrDB. Nucleic Acids Res. 2019;47(1):. https://doi.org/ 10.1093/nar/gky1084

52. Signer-Hasler $H$, Burren $A$, Neuditschko $M$, Frischknecht $M$, Garrick $D$, Stricker C, Gredler B, Bapst B, Flury C. Population structure and genomic inbreeding in nine Swiss dairy cattle populations. Genet Sel Evol. 2017;49(1):. https://doi.org/10.1186/s12711-017-0358-6.

53. ETH_Animal_Genomics. Github repository: Reference assembly choice. 2021. https://github.com/AnimalGenomicsETH/ Reference_assembly_choice. Accessed 13 Gen 2021.

54. Köster J, Rahmann S. Snakemake-a scalable bioinformatics workflow engine. Bioinformatics. 2012;28(19):2520-22. https://doi.org/10.1093/ bioinformatics/bts480.

55. Chen S, Zhou Y, Chen Y, Gu J. Fastp: An ultra-fast all-in-one FASTQ preprocessor. Bioinformatics. 2018;34(17):884-890. https://doi.org/10 1093/bioinformatics/bty560

56. Hernandez K. CLI for splitting a fastq that has multiple readgroups. 2020 https://github.com/kmhernan/gdc-fastq-splitter. Accessed 13 Gen 2021.

57. Li H, Durbin R. Fast and accurate short read alignment with Burrows-Wheeler transform. Bioinformatics. 2009;25(14):1754-60. https:// doi.org/10.1093/bioinformatics/btp324.

58. Li H. Aligning sequence reads, clone sequences and assembly contigs with BWA-MEM. 2013. http://arxiv.org/abs/1303.3997. Accessed 06 Apr 2021.

59. Faust GG, Hall IM. SAMBLASTER: Fast duplicate marking and structural variant read extraction. Bioinformatics. 2014;30(17):2503-5. https://doi. org/10.1093/bioinformatics/btu314.

60. Li H, Handsaker B, Wysoker A, Fennell T, Ruan J, Homer N, Marth G, Abecasis G, Durbin R. The Sequence Alignment/Map format and SAMtools. Bioinformatics. 2009;25(16):2078-9. https://doi.org/10.1093/ bioinformatics/btp352.

61. Tarasov A, Vilella AJ, Cuppen E, Nijman IJ, Prins P. Sambamba: fast processing of NGS alignment formats. 2015;31(12):2032-4. https://doi. org/10.5281/zenodo.13200.

62. Broad_Institute. Picard tools. 2021. http://broadinstitute.github.io/picard/. Accessed 13 Gen 2021.

63. Pedersen BS, Quinlan AR. Mosdepth: Quick coverage calculation for genomes and exomes. Bioinformatics. 2018;34(5):867-8. https://doi.org/ 10.1093/bioinformatics/btx699.
64. McKenna A, Hanna M, Banks E, Sivachenko A, Cibulskis K, Kernytsky A Garimella K, Altshuler D, Gabriel S, Daly M, DePristo MA. The genome analysis toolkit: A MapReduce framework for analyzing next-generation DNA sequencing data. Genome Res. 2010;20(9):1297-303. https://doi. org/10.1101/gr.107524.110.

65. Depristo MA, Banks E, Poplin R, Garimella KV, Maguire JR, Hartl C, Philippakis AA, Del Angel G, Rivas MA, Hanna M, McKenna A, Fennell TJ, Kernytsky AM, Sivachenko AY, Cibulskis K, Gabriel SB, Altshuler D, Daly MJ. A framework for variation discovery and genotyping using next-generation DNA sequencing data. Nat Genet. 2011;43(5):491-501. https://doi.org/10.1038/ng.806.

66. Chang CC, Chow CC, Tellier LCAM, Vattikuti S, Purcell SM, Lee JJ. Second-generation PLINK: Rising to the challenge of larger and richer datasets. GigaScience. 2015;4(1):. https://doi.org/10.1186/s13742-0150047-8.

67. Danecek P, Auton A, Abecasis G, Albers CA, Banks E, DePristo MA Handsaker RE, Lunter G, Marth GT, Sherry ST, McVean G, Durbin R. The variant call format and VCFtools. Bioinformatics. 2011;27(15):2156-8. https://doi.org/10.1093/bioinformatics/btr330.

68. Li H. Tabix: Fast retrieval of sequence features from generic TAB-delimited files. Bioinformatics. 2011;27(5):718-9. https://doi.org/10.1093/ bioinformatics/bta671.

69. Li H. A statistical framework for SNP calling, mutation discovery, association mapping and population genetical parameter estimation from sequencing data. Bioinformatics. 2011;27(21):2987-93. https://doi. org/10.1093/bioinformatics/btr509.

70. McLaren W, Gil L, Hunt SE, Riat HS, Ritchie GRS, Thormann A, FlicekP, Cunningham F. The Ensembl Variant Effect Predictor. Genome Biol. 2016;17(1):. https://doi.org/10.1186/s13059-016-0974-4.

71. Dainat J. AGAT: Another Gff Analysis Toolkit to handle annotations in any GTF/GFF format. 2021. Version v0.5.1. https://www.doi.org/10.5281/ zenodo.3552717. Accessed 15 Gen 2021

72. Degiorgio M, Huber CD, Hubisz MJ, Hellmann I, Nielsen R. SweepFinder2: Increased sensitivity, robustness and flexibility. Bioinformatics. 2016;32(12):1895-7. https://doi.org/10.1093/bioinformatics/btw051.

73. Quinlan AR, Hall IM. BEDTools: A flexible suite of utilities for comparing genomic features. Bioinformatics. 2010;26(6):841-2. https://doi.org/10. 1093/bioinformatics/bta033.

74. Harris RS. Improved Pairwise Alignment of Genomic DNA. PhD thesis, Pennsylvania State University, USA. 2007. https://dl.acm.org/doi/book/10. 5555/1414852.

75. Browning BL, Zhou Y, Browning SR. A One-Penny Imputed Genome from Next-Generation Reference Panels. Am J Hum Genet. 2018;103(3): 338-48. https://doi.org/10.1016/j.ajhg.2018.07.015.

76. Yang J, Lee SH, Goddard ME, Visscher PM. GCTA: A tool for genome-wide complex trait analysis. Am J Hum Genet. 2011;88(1):76-82. https://doi.org/10.1016/j.ajhg.2010.11.011.

\section{Publisher's Note}

Springer Nature remains neutral with regard to jurisdictional claims in published maps and institutional affiliations.

Ready to submit your research? Choose BMC and benefit from:

- fast, convenient online submission

- thorough peer review by experienced researchers in your field

- rapid publication on acceptance

- support for research data, including large and complex data types

- gold Open Access which fosters wider collaboration and increased citations

- maximum visibility for your research: over $100 \mathrm{M}$ website views per year

At BMC, research is always in progress.

Learn more biomedcentral.com/submissions 